\title{
Geochemistry of Carbonates on Mars: Implications for Climate History and Nature of Aqueous Environments
}

\author{
Paul B. Niles · David C. Catling · Gilles Berger · Eric Chassefière · Bethany \\ L. Ehlmann · Joseph R. Michalski · Richard Morris • Steven W. Ruff • Brad Sutter
}

Received: 20 January 2012 / Accepted: 29 September 2012 / Published online: 25 October 2012

(C) US Government 2012

\begin{abstract}
Ongoing research on martian meteorites and a new set of observations of carbonate minerals provided by an unprecedented series of robotic missions to Mars in the past 15 years help define new constraints on the history of martian climate with important cross-
\end{abstract}

P.B. Niles $(\varangle) \cdot$ R. Morris

Astromaterials Research and Exploration Science, NASA Johnson Space Center, Houston, TX 75080,

USA

e-mail: Paul.b.niles@nasa.gov

D.C. Catling

Department of Earth and Space Sciences/Astrobiology Program, University of Washington, Seattle, WA 98195, USA

G. Berger

IRAP, CNRS-Université Toulouse, 31400 Toulouse, France

E. Chassefière

Laboratoire IDES, UMR 8148, Université Paris-Sud, CNRS, 91405 Orsay, France

B.L. Ehlmann

Division of Geological and Planetary Sciences, California Institute of Technology, Pasadena, CA 91125, USA

B.L. Ehlmann

Jet Propulsion Laboratory, California Institute of Technology, Pasadena, CA 91109, USA

J.R. Michalski

Planetary Science Institute, Tucson, AZ 85719, USA

J.R. Michalski

Department of Mineralogy, Natural History Museum, London, UK

S.W. Ruff

School of Earth and Space Exploration, Arizona State University, Tempe, AZ, USA

B. Sutter

Jacobs ESCG, Houston, TX 77258-8447, USA 
cutting themes including: the $\mathrm{CO}_{2}$ budget of Mars, the role of $\mathrm{Mg}$-, Fe-rich fluids on Mars, and the interplay between carbonate formation and acidity.

Carbonate minerals have now been identified in a wide range of localities on Mars as well as in several martian meteorites. The martian meteorites contain carbonates in low abundances $(<1$ vol. $\%)$ and with a wide range of chemistries. Carbonates have also been identified by remote sensing instruments on orbiting spacecraft in several surface locations as well as in low concentrations (2-5 wt. \%) in the martian dust. The Spirit rover also identified an outcrop with 16 to 34 wt.\% carbonate material in the Columbia Hills of Gusev Crater that strongly resembled the composition of carbonate found in martian meteorite ALH 84001. Finally, the Phoenix lander identified concentrations of 3-6 wt.\% carbonate in the soils of the northern plains.

The carbonates discovered to date do not clearly indicate the past presence of a dense Noachian atmosphere, but instead suggest localized hydrothermal aqueous environments with limited water availability that existed primarily in the early to mid-Noachian followed by low levels of carbonate formation from thin films of transient water from the late Noachian to the present. The prevalence of carbonate along with evidence for active carbonate precipitation suggests that a global acidic chemistry is unlikely and a more complex relationship between acidity and carbonate formation is present.

Keywords Mars $\cdot$ Carbonate $\cdot$ Climate $\cdot \mathrm{CO}_{2} \cdot$ Water $\cdot$ Meteorites $\cdot$ Spectroscopy $\cdot$ Acidity $\cdot$ Atmosphere

\section{Introduction}

The history and distribution of water and carbon on Mars are closely related to the potential for life outside of the Earth (McKay et al. 1996). Carbonate minerals have long been seen as powerful tools with which to explore these fundamental relationships as they are intimately tied to both the water and the inorganic carbon cycle. Our understanding of the distribution and character of carbonates on the surface of Mars is undergoing rapid changes as several discoveries from recent robotic missions have clarified our view (Boynton et al. 2009; Ehlmann et al. 2008b; Morris et al. 2010). The nature and distribution of carbonates on Mars remains somewhat uncertain and subject to speculation, but some constraints can now be added. It now seems clear that carbonates do not exist as extensive, thick, laterally continuous bedrock units on the surface of the planet similar to those on Earth. Instead local deposits of carbonate have been discovered (Boynton et al. 2009; Ehlmann et al. 2008b; Morris et al. 2010), with the possibility of additional discoveries at smaller spatial scales or in mixed units excavated from the subsurface (Michalski and Niles 2010).

The wide ranging set of observations of carbonate minerals, provided by an unprecedented series of robotic missions to Mars in the past 15 years and ongoing research on martian meteorites, not only defines new constraints on the history of martian climate, but also opens unique windows into primordial martian aqueous environments. While questions about habitability remain unanswered at this time, we are obtaining more and more information about the environments in which water has existed on the martian surface. Here, we review the nature of carbonates detected in meteorites, from orbit, and from landed spacecraft. We then discuss the origin of these carbonates and the potential constraints that they can provide on the history of the martian climate and past environments. Based on this cumulative view of the studies of carbonate on Mars, several cross-cutting themes can be identified and discussed. The number of new discoveries of carbonate across the surface of the planet 
and the ongoing progress in analysis of carbonates in martian meteorites allow for new constraints to be placed on the martian $\mathrm{CO}_{2}$ budget. Chemical data from landed missions, orbital remote sensing, and martian meteorites suggest that $\mathrm{Mg}$-, Fe-rich carbonates may be more common on Mars and may have implications for martian aqueous environments. Finally, the work on carbonate formation has implications for planet-wide geochemical processes and especially the importance of acidic aqueous environments.

\section{Carbonates in Martian Meteorites/Atmospheric $\mathrm{CO}_{2}$ Isotopes}

There are more than 45 samples of Mars that have now been identified and characterized in our meteorite collections (Meyer 2011). All of these samples are igneous rocks and show some degree of weathering, frequently in the form of carbonate minerals and in low abundance (1\% or less) (Bridges et al. 2001). A strong case has been made that at least some of these samples contain carbonate that formed on Mars and thus preserve the chemical signatures of aqueous environments on that planet. Evidence for a martian origin includes nonterrestrial stable isotopic compositions, petrographical relationships, and atypical chemical compositions that would be extremely difficult to explain as terrestrial contamination (Mittlefehldt 1994; Romanek et al. 1994; Treiman 1995).

\subsection{Chemistry and Petrography of Carbonates}

The most widely studied and well understood martian carbonates come from meteorites ALH 84001 (4.1 Ga orthopyroxenite), Nakhla (1.3 Ga clinopyroxenite), Governor Valadares (1.3 Ga clinopyroxenite), Lafayette (1.3 Ga clinopyroxenite), and EETA 79001 (173 Ma basalt) (Nyquist et al. 2001) (see also Bouvier et al. 2008, and Bogard and Park 2008 on shergottite age controversy). These rocks contain carbonate phases that cover a diverse chemical range between calcite, magnesite, and siderite (Fig. 1). The carbonates typically occur as small crystals $(<100 \mu \mathrm{m})$ along cracks and within crushed zones of the rocks. They are sometimes associated with other aqueous alteration phases such as phyllosilicates, iron oxides, and iron sulfides (Bridges et al. 2001).

Fig. 1 Photograph of carbonate globules in ALH 84001. Orange central globules correspond to mixed $\mathrm{Ca}-\mathrm{Fe}-\mathrm{Mg}$-rich carbonate while the outer white rims correspond to $\mathrm{Mg}$-rich carbonate (photo credit Monica Grady)

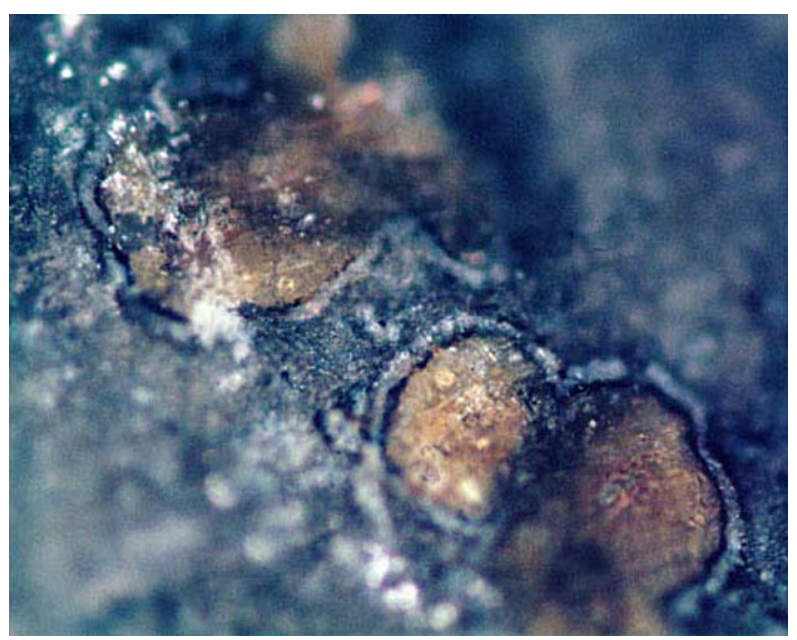




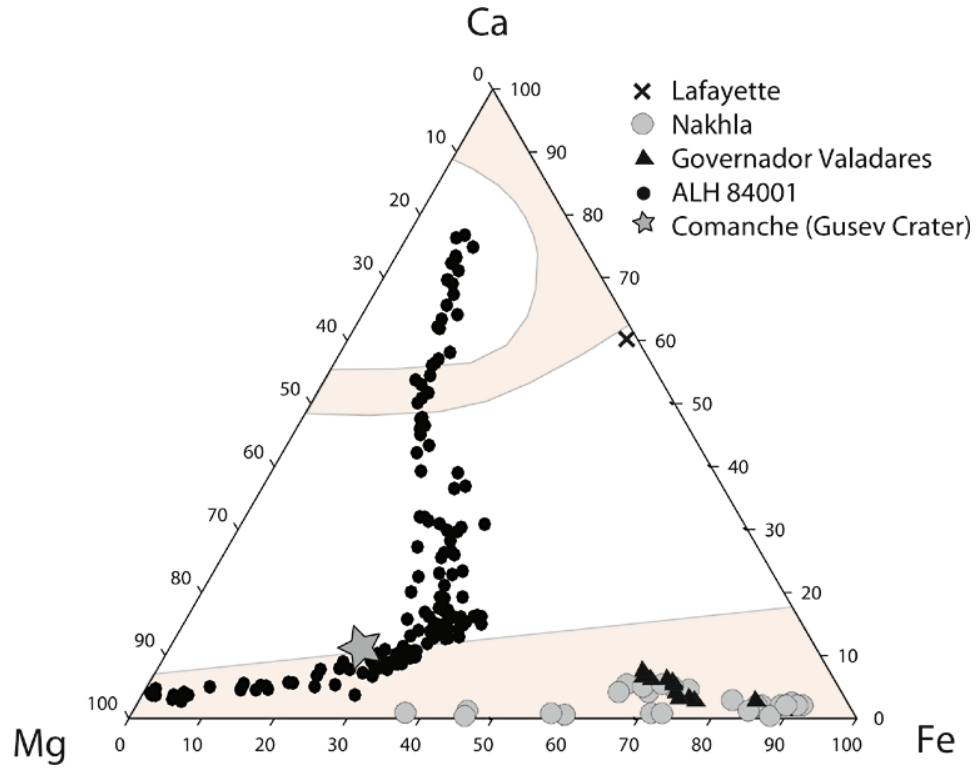

Fig. 2 Chemical composition of martian carbonates as reported in the literature. Figure is adapted from Bridges et al. (2001). The composition of the carbonate in the Comanche outcrop as measured by the Spirit rover (Morris et al. 2010) is also plotted here. The light orange fields are calculated stability fields for carbonate minerals at $700{ }^{\circ} \mathrm{C}$ (Anovitz and Essene 1987)

The carbonates found in ALH 84001 have unique chemical features which are extremely rare on Earth. ALH84001 is composed of less than $1 \%$ carbonate minerals (Mittlefehldt 1994), which appear in patches and as globules up to $\sim 300 \mu \mathrm{m}$ in diameter along annealed fractures in the rock as well as within the granular bands (Harvey and McSween 1996; Mittlefehldt 1994; Treiman 1995). The carbonates are orange colored and appear in a variety of different habits. The best-known type of carbonate is the zoned rosettes (Fig. 1), which are pancake shaped and have well-defined Mg-rich rims. These rosettes exhibit strong chemical zoning (Harvey and McSween 1996). Typical concentric chemical zoning consists of an inner core of ankerite ( $\mathrm{Ca}, \mathrm{Fe}$ carbonate) or $\mathrm{Ca}, \mathrm{Fe}, \mathrm{Mg}$ solid solution carbonate, which gradually transitions to white magnesite at the rims (Figs. 1, 2) (Corrigan and Harvey 2004). The carbonates also possess unique bands of micro-scale magnetite crystals that are narrowly concentrated around the outer edges of the carbonate globule.

Among the nakhlites, three pre-terrestrial, chemically distinct populations of carbonate have been measured (Fig. 2). Gooding et al. (1991) reported vein filling carbonate that is very close to pure $\mathrm{CaCO}_{3}$. This has not been reported in any other subsequent studies but may be reflected in isotope analyses (see Sect. 2.2 below). Both Nakhla and Governor Valadares contain $\mathrm{Ca}$-poor and $\mathrm{Fe}$-rich siderite crystals which are typically associated with silicate alteration zones. Lafayette contains Mn-rich siderite which is chemically distinct from the carbonates in Nakhla and Governor Valadares (Bridges and Grady 2000).

The chemical compositions of the ALH 84001 and Lafayette carbonates lie outside of any known equilibrium stability fields (Fig. 2) and have a mixed $\mathrm{Ca}, \mathrm{Fe}, \mathrm{Mg}$ composition that is commonly found in low temperature diagenetic concretions on Earth (Mozley 1989). This is the result of kinetic effects associated with the dehydration of Mg (Lippmann 1973) and rapid crystallization (Valley et al. 1997). The composition is consistent with other evidence 


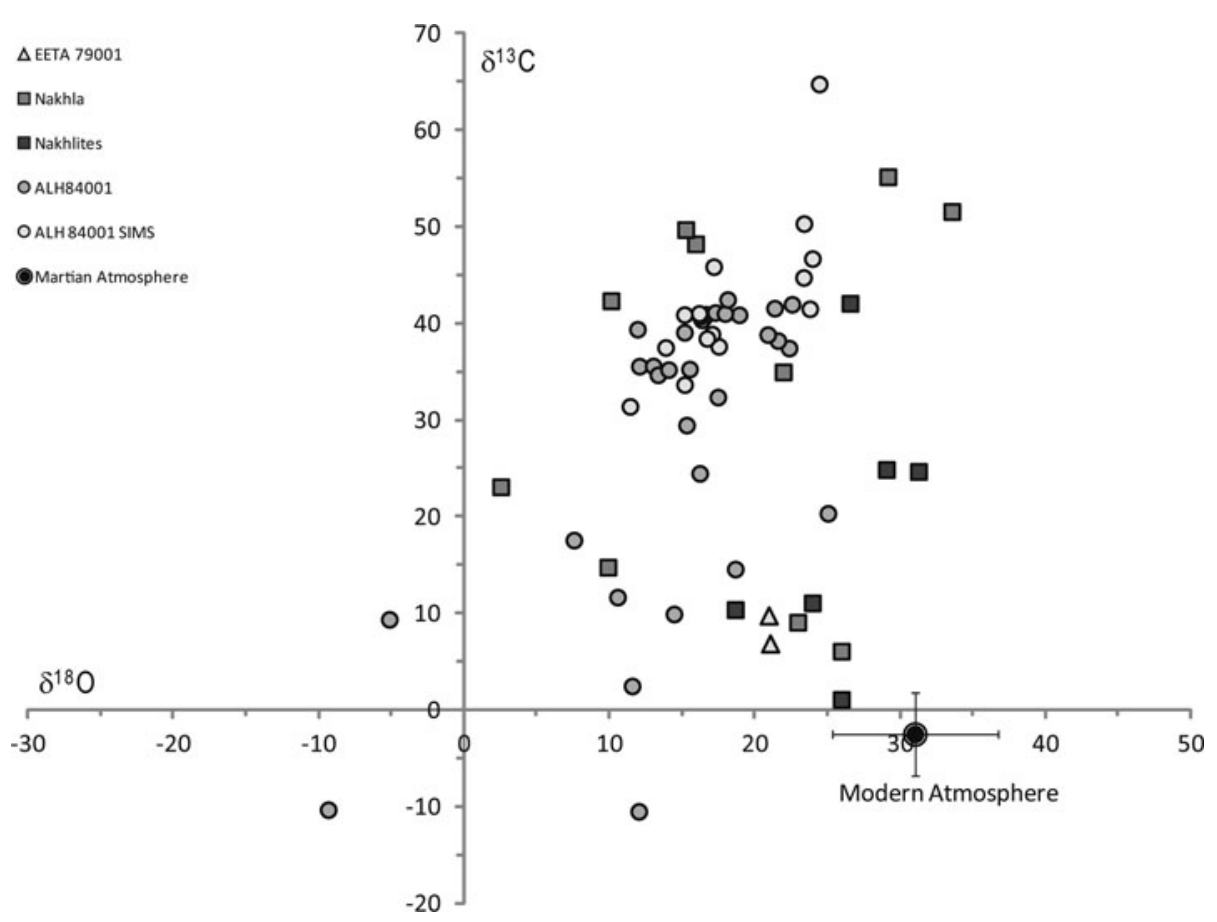

Fig. 3 Carbon and oxygen isotope cross-plot of martian meteorite carbonates after Niles et al. (2010). Data points reflect individual measurements of $\mathrm{CO}_{2}$ liberated by interaction with phosphoric acid. The scatter in the data likely reflects the variety of different carbonate phases within the martian meteorites. These multiple episodes vary strongly in carbon isotopes and may reflect evolution of the martian atmosphere through time

that suggests that the carbonate-forming aqueous systems were short lived and subject to dynamic environmental changes (Changela and Bridges 2011; Niles et al. 2005; Valley et al. 1997). Experimental work performed to date has succeeded in forming carbonates with a similar chemical composition as the ALH 84001 carbonates (Golden et al. 2000, 2001), but not with the correct variation in isotopic composition. Likewise, analogous carbonates from Spitsbergen show similar chemical compositions but do not show similar isotopic variation (Treiman et al. 2002). Thus far no single laboratory process has been able to re-create both the chemical and isotopic compositions of the ALH 84001 carbonates.

\subsection{Carbon and Oxygen Stable Isotopic Compositions of the Carbonates}

The carbonates contained in martian meteorites have isotopic compositions that can be highly variable on the micro-scale (Valley et al. 1997) and also contain highly enriched carbon isotope compositions with $\delta^{13} \mathrm{C}$ values as high as $+64 \% 0$-much more enriched than sedimentary carbonates on Earth, which rarely exceed $10 \%$ (Knauth and Kennedy 2009; Niles et al. 2005; Romanek et al. 1994). The isotopic compositions have been measured using a variety of techniques including acid dissolution, pyrolysis-IRMS, and Secondary Ion Mass Spectrometry (SIMS). So far, only the acid dissolution technique allows for paired $\delta^{13} \mathrm{C}$ and $\delta^{18} \mathrm{O}$ analyses of the same sample and the results from those analyses are widely scattered (Fig. 3). Some of this scatter is likely due to the differences in carbonate chemistry (discussed above) and the different measurement methods used in each study. Some is also 
Fig. 4 Ion probe analyses of ALH 84001 carbonates reported in the literature and plotted versus magnesium composition of the analysis spot. Uncertainties on each data point range between 1 to $5 \%(2 \sigma)$ depending on the study.

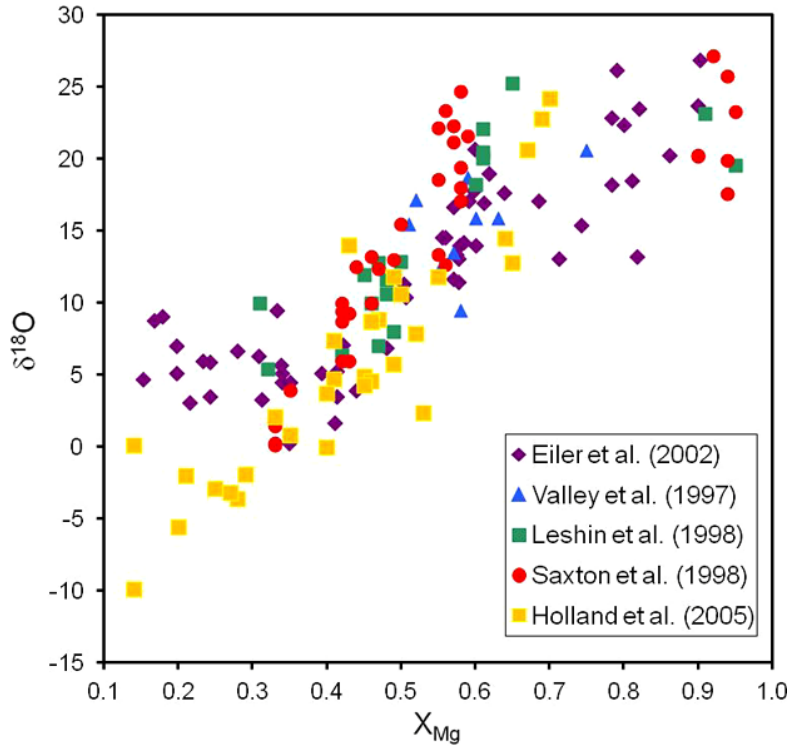

likely due to terrestrial contamination especially in the meteorites collected in Antarctica. Nevertheless, it is clear from this work that ALH 84001 and the nakhlites have carbonates with very high $\delta^{13} \mathrm{C}$ (>40 \%) (Jull et al. 1995, 2000; Romanek et al. 1994) compared to the composition of the modern martian atmosphere $\left(\delta^{13} \mathrm{C}=-2.5 \pm 4.3 \%\right.$ ) (Krasnopolsky et al. 2007; Niles et al. 2010).

SIMS analyses allow for in-situ micro-scale measurement of isotopic composition and can therefore pair isotopic compositions with chemical compositions measured by electron microprobe. The results of these analyses for ALH 84001 show a wide variation in both $\delta^{18} \mathrm{O}$ and $\delta^{13} \mathrm{C}$ correlated with chemical composition (Fig. 4) (Eiler et al. 2002; Holland et al. 2005; Leshin et al. 1998; Niles et al. 2005; Saxton et al. 1998; Valley et al. 1997). The early-forming, Ca-rich phases were found to have the lowest $\delta^{18} \mathrm{O}$ and $\delta^{13} \mathrm{C}$ values and the $\mathrm{Mg}$-rich, later-forming phases were found to have the highest $\delta^{18} \mathrm{O}$ and $\delta^{13} \mathrm{C}$ values (Leshin et al. 1998). The ALH 84001 carbonates have also been recently analyzed for their clumped isotope composition which suggests the carbonates formed between 14 and $22{ }^{\circ} \mathrm{C}$ in an evaporative environment (Halevy et al. 2011). The strong dependence of $\delta^{18} \mathrm{O}$ and chemical composition is used to calculate $\delta^{18} \mathrm{O}$ compositions for the published $\delta^{13} \mathrm{C}$ data (Halevy et al. 2011). These values are plotted in Fig. 3 to compare the different analysis techniques which agree well.

Finally, triple oxygen isotope analyses of carbonates in Nakhla, Lafayette, and ALH 84001 have shown that carbonates in these meteorites have a large $\Delta^{17} \mathrm{O}$ anomaly indicating that they formed from an atmospheric oxygen reservoir with limited contact with the silicate crust (Farquhar and Thiemens 2000; Farquhar et al. 1998). This not only confirms that these carbonates have a martian origin, but that they formed from water that was more closely associated with the atmosphere than with the silicate rocks. Thus it is unlikely that the carbonates formed from water derived from a subsurface hydrothermal system that was isolated from the atmosphere or long lived groundwater system. Instead, the data favor formation environments that featured ice or rain that had been out of contact with the silicate crust for long periods (Farquhar and Thiemens 2000; Farquhar et al. 1998). Geothermal heating that melted ice and mobilized saline fluids with 
limited water-rock interaction is a possible way to reconcile the inferences of atmospheric influence from triple oxygen isotope analysis with data suggesting a subsurface environment for the veined carbonates (e.g., Changela and Bridges 2011).

\subsection{Formation Environments and Insight into Martian Climate History}

A large number of studies have focused on the formation environment of the ALH 84001 carbonates, and two dominant competing views have emerged synthesizing all or most of the available evidence. One hypothesis contends that the ALH 84001 carbonates have a number of characteristics that indicate their low temperature $\left(<\sim 100{ }^{\circ} \mathrm{C}\right)$ deposition in a dynamic environment during perhaps several different episodes (Corrigan and Harvey 2004; Halevy et al. 2011; Holland et al. 2005; McSween and Harvey 1998; Niles et al. 2005, 2009; Valley et al. 1997; Warren 1998). Another hypothesis suggests that the carbonates formed in a rapidly cooling environment which was initially at higher temperature $\left(>150{ }^{\circ} \mathrm{C}\right)$ and cooled to $\sim 30{ }^{\circ} \mathrm{C}$ (Eiler et al. 2002; Leshin et al. 1998; Romanek et al. 1994; Steele et al. 2007), although this is now directly disputed by recently reported clumped isotope results (Halevy et al. 2011).

Both scenarios have features in common, including an aqueous system that is short lived, largely low temperature $\left(<100^{\circ} \mathrm{C}\right)$, dynamically changing, and involves very small amounts of fluid. Neither scenario supports long lived aqueous environments created by warm climatic conditions. Evidence for silicate weathering in ALH 84001 is conspicuously absent for such an old rock (Treiman 1995), supporting the idea that any sustained warm and wet conditions on Mars were likely localized if present at all. Both formation scenarios also suggest that the elevated $\delta^{13} \mathrm{C}$ values seen in the $\mathrm{ALH} 84001$ carbonates are derived from the atmosphere at that time, suggesting that the carbon isotopic composition of the atmosphere at $\sim 4.0 \mathrm{Ga}$, which corresponds to the beginning of the Noachian (Frey 2006), was much different from the carbon isotopic composition of the modern atmosphere (Niles et al. 2010).

One possible explanation for the carbon isotope enrichment in the ALH 84001 and nakhlite carbonates is through preferential atmospheric loss of ${ }^{12} \mathrm{C}$ in the Noachian following the loss of the magnetic field $>4 \mathrm{Ga}$ (Jakosky et al. 1994). Atmospheric loss would act to increase the $\delta^{13} \mathrm{C}$ of the atmosphere early in martian history while the Sun's extreme ultraviolet (EUV) flux remained elevated (Jakosky et al. 1994). However, as the Sun's EUV flux decreased with time, volcanic degassing and carbonate deposition became the dominant processes, bringing the $\delta^{13} \mathrm{C}$ of the atmospheric $\mathrm{CO}_{2}$ back down closer to magmatic values (Grott et al. 2011; Manning et al. 2006; Niles et al. 2010). Another more speculative possibility for the enrichment of ${ }^{13} \mathrm{C}$ in the early atmosphere is that Mars originally had a methane-dominated reduced early atmosphere and minor $\mathrm{CO}_{2}$ in equilibrium with this atmosphere would have $\delta^{13} \mathrm{C}$ values near $+35 \%$ due to the mass balance between $\mathrm{CO}_{2}$ and $\mathrm{CH}_{4}$ (Galimov 2000). A similar mechanism has also been proposed for a terrestrial deposit of $\delta^{13} \mathrm{C}$-rich carbonates $(+5.4 \%$ to $+19.0 \%$ ) associated with natural gas-rich shales (Murata et al. 1967). Finally, the possibility exists that the magmatic $\mathrm{CO}_{2}$ on Mars is substantially enriched in ${ }^{13} \mathrm{C}$ compared to the Earth. However, this is not supported by measurements from martian meteorites which in fact suggest that the carbon isotopic content of magmatic carbon on Mars is depleted in ${ }^{13} \mathrm{C}$ compared to the Earth (Wright et al. 1992). No other mechanisms have been proposed that might explain an enrichment in $\delta^{13} \mathrm{C}$ of $>50 \%$ for the magmatic $\mathrm{CO}_{2}$ contained within the planet, and given the available evidence, it is most likely that the $\delta^{13} \mathrm{C}$ of the martian atmosphere has changed substantially through martian history as a result of atmospheric loss, carbonate formation, and volcanic degassing. 
Nakhla and the Nakhlite meteorite group have been interpreted to derive from different depths of a shallow layered igneous flow or intrusion. This is based on their mineralogy and groundmass textures (Reid and Bunch 1975) as well as variations in their secondary mineralogy (Bridges and Warren 2006). Particularly, Yamato 00593 shows evidence for faster cooling and fewer cumulus phases (Mikouchi et al. 2003) while Lafayette is considered to have cooled the slowest. Furthermore the secondary phases in the nakhlites are not evenly distributed, perhaps also reflecting different source depths in the original cumulate pile (Changela and Bridges 2011).

The different secondary mineral populations in each meteorite have been interpreted to reflect an evolving evaporative environment where Lafayette contained the least soluble phases (most likely derived from initial evaporation) and Nakhla represented the most soluble phases reflecting the highest degree of evaporation. More recently a hydrothermal model has been proposed that suggests that fluids of moderate temperatures $\left(<150{ }^{\circ} \mathrm{C}\right)$ were mobilized from subsurface ice deposits, progressively altering the rocks in the cumulate pile during ascent and evaporation at the surface (Changela and Bridges 2011). Under this model, the elevated $\delta^{13} \mathrm{C}$ values in the nakhlite carbonates were likely obtained through a remobilization of more ancient carbonate deposits (Niles et al. 2010) rather than through exposure to the atmosphere during the time of their formation, and the $\Delta^{17} \mathrm{O}$ anomaly was inherited from the water source being atmospherically derived.

\section{Carbonates Detected on Mars}

The identification of carbonates on Mars was for many years limited to those found in the martian meteorites. No carbonates were found in the first global search undertaken with the Thermal Emission Spectrometer (TES) on the Mars Global Surveyor (Christensen et al. 2001). The TES instrument produced near global coverage in the thermal infrared (TIR) region $\left(\sim 6-50 \mu \mathrm{m}, 1670-2000 \mathrm{~cm}^{-1}\right)$ at a spatial resolution of $\sim 3 \times 6 \mathrm{~km}$ but did not detect any large-scale (10's of kilometers) occurrences of carbonates at abundances greater than $\sim 10 \%$ (Christensen et al. 2001). This included the long considered candidate on the floor of Pollack crater known as "White Rock" (Ruff et al. 2001). However, TIR spectra show evidence for a low abundance of carbonate minerals in the globally homogenous dust (Sect. 3.1). Subsequent higher resolution observations in the near IR have provided numerous detections of carbonate minerals at the outcrop scale (Sect. 3.2; Fig. 5). In addition, both the Phoenix lander and Spirit rover have detected carbonates on the surface of Mars (Sect. 4). Unfortunately, extensive ground-truthing of remote sensing observations has not occurred, making comparison between remote sensing observations, and landed or samplebased observations difficult to understand.

\subsection{Carbonates in Martian Dust}

Martian dust is continuously carried into suspension by eolian activity and distributed around the planet through the atmosphere until it settles and accumulates on the surface. TIR measurements of this dust from orbit and by the two Miniature Thermal Emission Spectrometers (Mini-TES) onboard the Mars Exploration Rovers (MER) have demonstrated a common spectral character that suggests uniform mineralogy and particle size wherever the dust is observed (Christensen et al. 2004; Yen et al. 2005). Bandfield et al. (2003) measured TIR spectra of physical mixtures of labradorite as a proxy for martian dust combined with various carbonate minerals and found that a small amount ( $\sim 2$ to 5 weight $\%$ ) of fine-particulate 


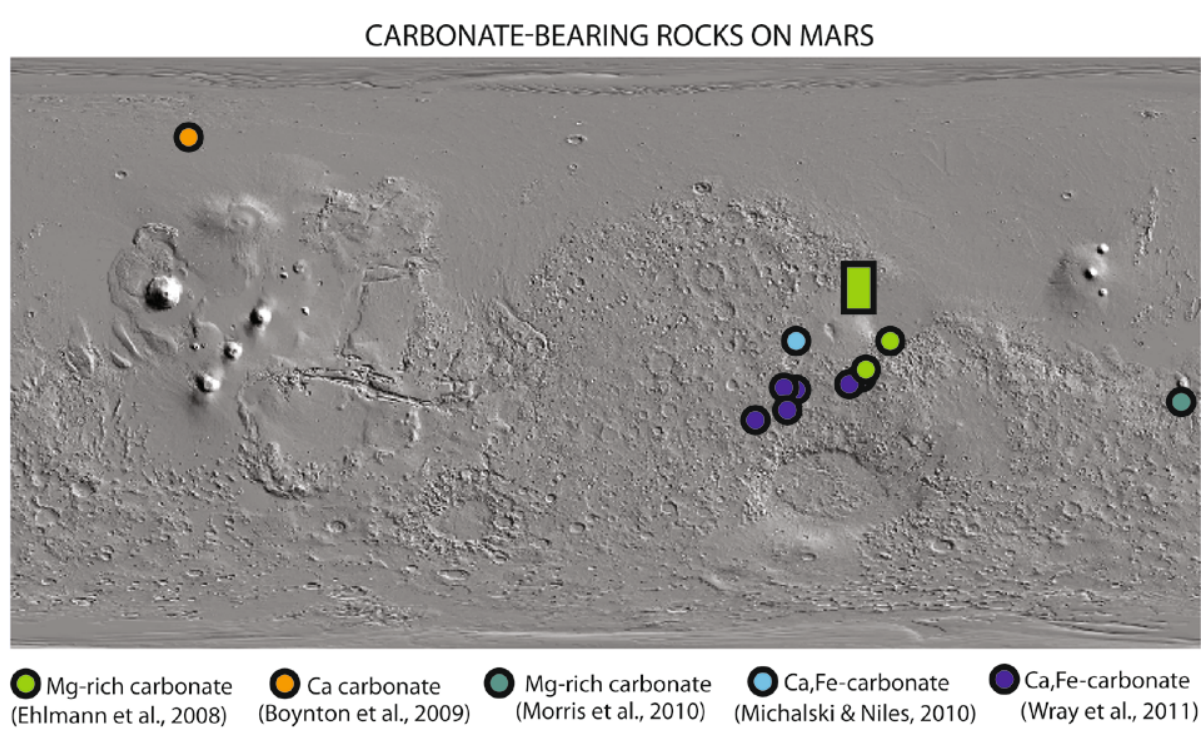

Fig. 5 Map of identified carbonate locations on Mars

magnesite ( $<10$ micron) provided the best fit to distinctive features above $1300 \mathrm{~cm}^{-1}$ in TES spectra of dust. Typically such a small abundance of carbonate would not be detectable, but silicates are relatively transparent at high wavenumbers where carbonates exhibit an emissivity peak near $1500 \mathrm{~cm}^{-1}(\sim 6.5 \mu \mathrm{m})$ that arises due to intense volume reflections at the frequency of C-O stretching vibrations. This is not observed in other mineral groups besides hydrous iron sulfates discussed below; therefore, the emissivity peak in the martian dust is interpreted as evidence for a carbonate admixture in fine-grained silicate material.

The precise wavelength of the emissivity peak is an indication of the composition of the carbonate. Different cations within the carbonates, typically $\mathrm{Mg}^{2+}, \mathrm{Ca}^{2+}$, or $\mathrm{Fe}^{2+}$, affect the bond lengths and vibrational frequency of the $\mathrm{C}-\mathrm{O}$ bonds. The position of the emissivity peak at $6.5 \mu \mathrm{m}$ in TES spectra of martian dust is most consistent with the presence of $\mathrm{Mg}$ carbonates (Bandfield et al. 2003). Although the abundance of carbonate in martian dust appears low, the ubiquity and uniformity of dust across Mars suggest that it may represent a sink as large as 1-3 bars for atmospheric $\mathrm{CO}_{2}$ (Bandfield et al. 2003) (see Sect. 6.1 below).

Lane et al. (2004) showed with laboratory data that a similar spectral shape in the $6.5 \mu \mathrm{m}$ region could be achieved if hydrous iron sulfates (HIS) are present in the dust, however, the spectral feature at $6.5 \mu \mathrm{m}$ is much weaker in the dust mixtures containing sulfate than it is in mixtures containing carbonate. Therefore the detection of carbonate in the fine grained dust remains the best explanation for the spectral data presented thus far, but it does not rule out some contribution that might be made by HIS. Measurements made by MSL (Mass Science Laboratory) will help clarify this issue.

\subsection{Carbonates Detected on the Surface by Remote Sensing}

Despite the dominance of volcanic and impact-related landforms, Mars also displays a complex sedimentary record (Malin and Edgett 2000). Spectroscopic data have revealed a diverse suite of silicate and sulfate alteration minerals associated with martian rocks and sediments. In contrast, spectroscopic detection of carbonates has proved challenging, and only 
recently have data shown the first robust detections. Known occurrences of carbonates detected from orbit can be categorized as: layered-to-massive, irregular deposits of Mg-rich carbonates in olivine-bearing Noachian bedrock units (Ehlmann et al. 2008b), sedimentary deposits that host Fe/Mg smectite clays and carbonates (Ehlmann et al. 2008a, 2009), and layered carbonate-bearing rocks exhumed from several kilometers depth in the crust by impact (Michalski and Niles 2010).

Layered-to-massive deposits of carbonates were detected in Noachian terrains using near-infrared reflectance data from the Compact Reconnaissance Imaging Spectrometer for Mars (CRISM) (Ehlmann et al. 2008b). While 1000s of CRISM images have been analyzed in search for carbonates (Murchie et al. 2009), the detections to date are generally limited to the well-exposed, ancient terrain around the Nili Fossae and slightly further south in Libya Montes and Terra Tyrrhena (Ehlmann et al. 2008b). Throughout this region, the oldest part of the stratigraphy, where visible, consists of Fe-Mg smectite clay and low-calcium pyroxene bearing materials. The Fe/Mg-clay unit is overlain by olivine-rich materials interpreted as impact cumulates from the Isidis melt sheet or fluid, komatiite-like lavas. Moving up in section, an aluminous clay-bearing unit is occasionally present, which is in turn overlaid by a dark, mafic capping unit. The carbonate detections are typically located within the olivinerich stratigraphic unit. The carbonate is always stratigraphically above the Fe/Mg-clay unit. The relationship between carbonate and aluminous clays is not easily correlated; however, carbonates sometimes underlie the aluminous clays (Ehlmann et al. 2008b, 2009; Mustard et al. 2009). Because of their association with the olivine-rich unit that postdates the Isidis impact and capping by Syrtis Major volcanics that formed in the Early Hesperian (Hiesinger and Head 2004), the carbonates are interpreted as Noachian materials. Sedimentary paleolake deposits within Jezero crater also contain carbonates associated with Fe/Mg smectites. These clays and carbonates are likely to have been transported, rather than forming in situ in a standing body of water, because they are identical to mineralogic units found in the highlands of the crater's watershed (Ehlmann et al. 2008a).

The evidence for carbonate from CRISM data rests in the co-occurrence of spectral absorptions related to $\mathrm{C}-\mathrm{O}$ vibrational overtones located at $(\lambda=)$ 2.3-2.35, 2.5-2.54, 3.4, and $3.9 \mu \mathrm{m}$ (Fig. 6) (Calvin et al. 1994; Ehlmann et al. 2008b; Gaffey 1987). As in the thermal infrared, the location of these features is an indication of composition of the carbonates for the same reasons outlined in Sect. 3.1 above. In the case of Nili Fossae carbonates, the band positions at $2.31 \mu \mathrm{m}$ and $2.51 \mu \mathrm{m}$ are most consistent with Mg-rich carbonates similar to magnesite, that are hydrated and have only a minor amount of Fe or Ca substitution (Brown et al. 2010). Spectral mixing in the near infrared is nonlinear, and the strengths of spectral absorptions are not a clear indication of mineral abundance.

Three hypotheses have been proposed to explain the origin of the Nili-Fossae-type carbonates. One possibility is that the clay and carbonate units formed simultaneously in a single deep hydrothermal system in zones of different temperature and fluid composition (Brown et al. 2010; van Berk and Fu 2011). A second variant of the hydrothermal model is that the $\mathrm{Mg}$ carbonate formed in the shallow subsurface due to diagenetic or low-T hydrothermal alteration of olivine, sometimes in the presence of $\mathrm{CO}_{2}$; this may be consistent with the occasional detection of serpentine associated with the olivine unit (Ehlmann et al. 2009). The third possibility is that surface weathering occurred, potentially in association with enhanced precipitation and runoff near the end of the Noachian (Ehlmann et al. 2009).

Carbonates have also been detected from orbit within impact craters, in rocks exhumed from deep in the martian crust by impact (Michalski and Niles 2010). The deep crust of Mars is generally poorly exposed because of the lack of a plate tectonic-like mechanism to drive 


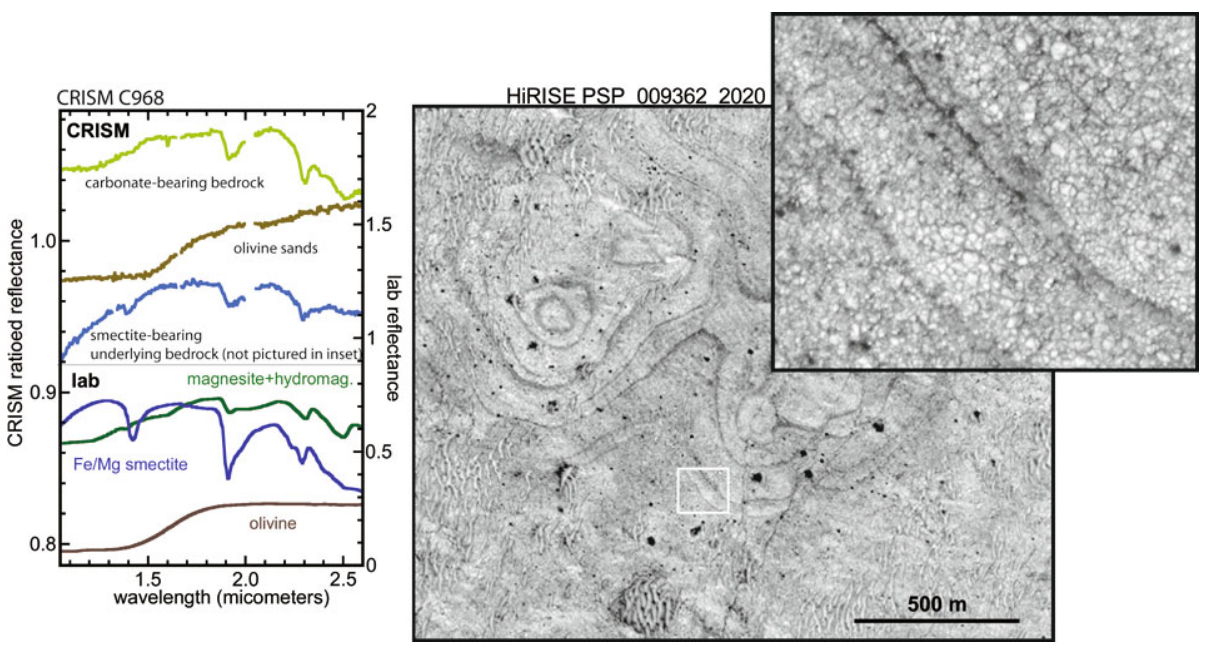

Fig. 6 Carbonate plains in Nili Fossae. A distinctive stratigraphy of olivine and carbonate-bearing rocks overlying $\mathrm{Fe} / \mathrm{Mg}$ smectite bearing rocks are observed throughout the region, partially obscured by olivine sands. Inset image is $150 \mathrm{~m}$ wide and the carbonate bearing bedrock has a banded appearance (Mustard et al. 2009) and is fractured at a few meter scale. [Credits: NASA/UA/HiRise and NASA/JPL/JHUAPL/CRISM]

uplift and resurfacing. One exception is within the central peaks of impact craters, which sample crust at a depth roughly 1/10 the diameter of the crater (Cintala and Grieve 1998; Pilkington and Grieve 1992). Leighton crater, located southwest of the Syrtis Major region of Mars, shows carbonates exhumed from $\sim 6 \mathrm{~km}$ depth that are different from those observed in the previously described categories because these deep carbonates appear to be $\mathrm{Ca}$ - and/or Fe-rich rather than Mg-rich, as determined by band centers at 2.35 and $2.53 \mu \mathrm{m}$ (Michalski and Niles 2010). They occur in discrete layers, though these layers were highly deformed and disrupted by the impact event. Carbonates may also be a component of the surrounding phyllosilicate-bearing bedrock, which contains evidence for low-T hydrothermal or metamorphic minerals such as prehnite, pumpellyite or chlorite, and chlorite-smectite mixed layer clays.

Several hypotheses have been proposed to explain the occurrence of these deep carbonates (Michalski and Niles 2010). The most likely scenario is that a stratigraphic section of $\mathrm{Fe} / \mathrm{Mg}$-rich clays overlaid by carbonates and then by aluminous clays existed in this region, and that section was buried to great depth by volcanic flows from volcanism in Syrtis Major. Low-T metamorphism occurred due to the higher thermal gradient at that time, and due to heat supplied by the overlying volcanics. A second hypothesis resembles the near-surface hydrothermal alteration proposed for Nili Fossae (Ehlmann et al. 2008b, 2009) and suggests that $\mathrm{CO}_{2}$-rich fluids descended from the surface and altered the deep (5-10 km) basaltic crustal material upon mixing with deep, reduced crustal fluids. However, the ability to transport sufficient amounts of $\mathrm{CO}_{2}$ from the surface to depth remains a hurdle for this model (Michalski and Niles 2010).

Recent analyses have suggested that carbonates mixed with clay minerals are exposed in more craters throughout the southern Nili Fossae-Terra Tyrrhena region (Wray et al. 2011). Regardless of the mechanism by which they formed, these materials hint at a possible deep cache of carbonate hidden from view that may account for a significant amount of $\mathrm{CO}_{2}$ sequestered from the atmosphere. 


\section{Carbonates Detected In Situ}

\subsection{Comanche Carbonate at Gusev Crater}

The Mars Exploration Rover (MER) Spirit identified outcrops rich in $\mathrm{Mg}$-Fe carbonate (16 to $34 \mathrm{wt} . \%$ ) on the southern slope of Haskin Ridge in the Columbia Hills of Gusev crater (Fig. 7) (Morris et al. 2010). The carbonate identification in the Comanche outcrops is based on the aggregate of mineralogical and chemical data from Spirit's Mössbauer spectrometer (MB), Miniature Thermal Emission Spectrometer (Mini-TES), and Alpha Particle X-Ray Spectrometer (APXS). The excess of light elements (e.g., $\mathrm{H}_{2} \mathrm{O}, \mathrm{CO}_{2}$, or $\mathrm{NO}_{2}$ ) from APXS has been interpreted as carbonate on the basis of the mineralogical identifications of the phase by MB and Mini-TES. Assignment of the carbonate to $\mathrm{Mg}$ Fe-rich carbonate was based on the intersection of the combined constraints of MB (MgFe-rich carbonate), Mini-TES (Ca-Mg-rich carbonate), and APXS (low total Ca concentration). The combined MB and APXS data were used to calculate a chemical composition of $\mathrm{Mc}_{0.62} \mathrm{Sd}_{0.25} \mathrm{Cc}_{0.11} \mathrm{Rh}_{0.02}$ for the Comanche carbonate, where $\mathrm{Mc}=$ magnesite $\left(\mathrm{MgCO}_{3}\right)$, $\mathrm{Sd}=$ siderite $\left(\mathrm{FeCO}_{3}\right), \mathrm{Cc}=$ calcite $\left(\mathrm{CaCO}_{3}\right)$, and $\mathrm{Rh}=$ rhodochrosite $\left(\mathrm{MnCO}_{3}\right)$. This composition is very similar to the average composition of carbonate found in martian meteorite $\mathrm{ALH} 84001$ of $\mathrm{Mc}_{0.58} \mathrm{Sd}_{0.29} \mathrm{Cc}_{0.12} \mathrm{Rh}_{0.01}$ at $\sim 1$ wt.\% abundance (Mittlefehldt 1994; Treiman 1995) (see also Fig. 2).

Independent calculations using combined MB data, APXS data, and Mini-TES data provide the basis for estimating that carbonate is a major component of the Comanche outcrops at 16 to $34 \mathrm{wt} . \%$. The remote sensing capability of the Mini-TES instrument shows that the carbonate is present throughout the visible Comanche outcrops $\left(\sim 50 \mathrm{~m}^{2}\right)$ and not just at the two small MB and APXS analysis spots (7 to $30 \mathrm{~cm}^{2}$ ).

Other phases associated with the Comanche carbonate are olivine, npOx, and hematite (49 \%, $19 \%$, and $8 \%$ of total Fe, respectively) according to MB and olivine (Fo68) and amorphous silicate (33\% and $33 \%$, respectively) according to Mini-TES (Morris et al. 2010). Recently, a mixture of Mg-rich carbonate and olivine also was identified in the region of the Comanche outcrops using spectra from the CRISM instrument (Carter and Poulet 2012). The carbonate detections by MER and CRISM at Gusev crater and by CRISM at Nili Fossae (Ehlmann et al. 2008b) thus have in common Mg-Fe-rich chemistry and an association with olivine. Assuming the hematite associated with the Comanche carbonate is a

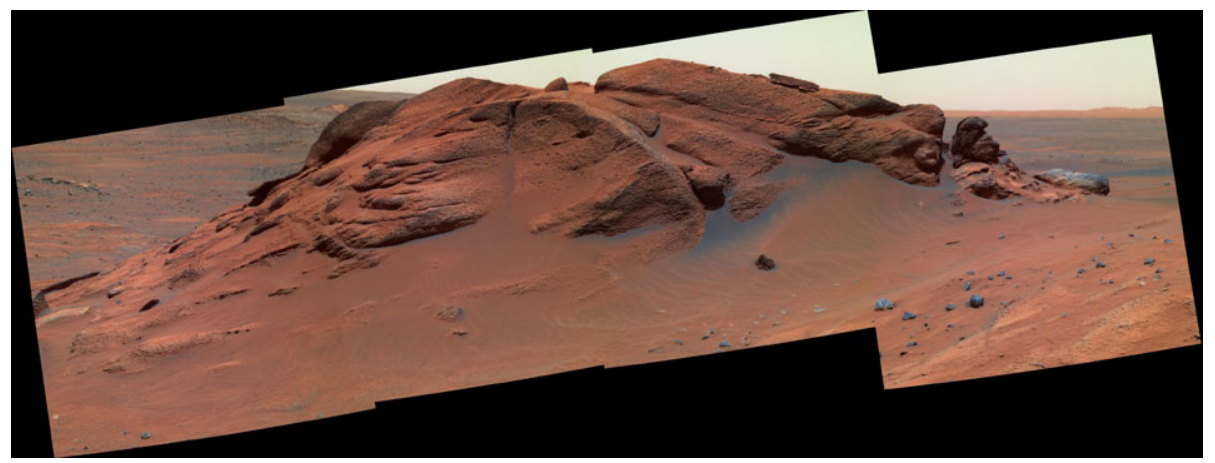

Fig. 7 Pancam false color mosaic of the Comanche outcrop on Gusev crater Mars. Spirit rover sol 695, Pancam sequence P2422 [Credit: NASA/JPL/Pancam] 
precipitation product and not a thermal oxidation product of pre-existing magnetite, precipitation of the carbonate and oxides under conditions of low water activity (e.g., hydrothermal and/or cryogenic conditions and/or concentrated brines) are implied. Low water activity of a Mg-rich fluid is the favored condition for Mg-rich carbonates to be formed (see Sect. 6.2, below).

\subsection{Phoenix Landing Site Carbonates}

The Phoenix Mars lander analyzed several samples of the martian soil in the north polar region near $68^{\circ} \mathrm{N}$ (Smith et al. 2009b). One of the instruments used in the analysis was the Thermal and Evolved Gas Analyzer (TEGA), which consisted of a high temperature furnace paired with a magnetic sector mass spectrometer. Results from the TEGA analyses were consistent with the detection of carbonate minerals within the soils near the lander, and this was corroborated by analyses from the Wet Chemistry Laboratory (WCL) on the same lander (Boynton et al. 2009; Kounaves et al. 2010a).

TEGA measured an endotherm between $725^{\circ}$ and $820^{\circ}$ with a corresponding $\mathrm{CO}_{2}$ release that was consistent with the presence of 3 to $6 \%$ calcite, ankerite, dolomite, and/or another calcium-rich carbonate in the Phoenix landing site soil (Fig. 8) (Boynton et al. 2009; Sutter et al. 2012). In addition, the soil $\mathrm{pH}(7.7 \pm 0.3),\left[\mathrm{Ca}^{2+}\right]$, and $\left[\mathrm{Mg}^{2+}\right]$ measured by the WCL instrument is consistent with the presence of carbonate minerals in the soil (Kounaves et al. 2010b). TEGA also detected a release of $\mathrm{CO}_{2}$ at a low temperature (between $400^{\circ}$ and $680{ }^{\circ} \mathrm{C}$ ) that has been interpreted to be due to either $\mathrm{Fe}, \mathrm{Mg}$

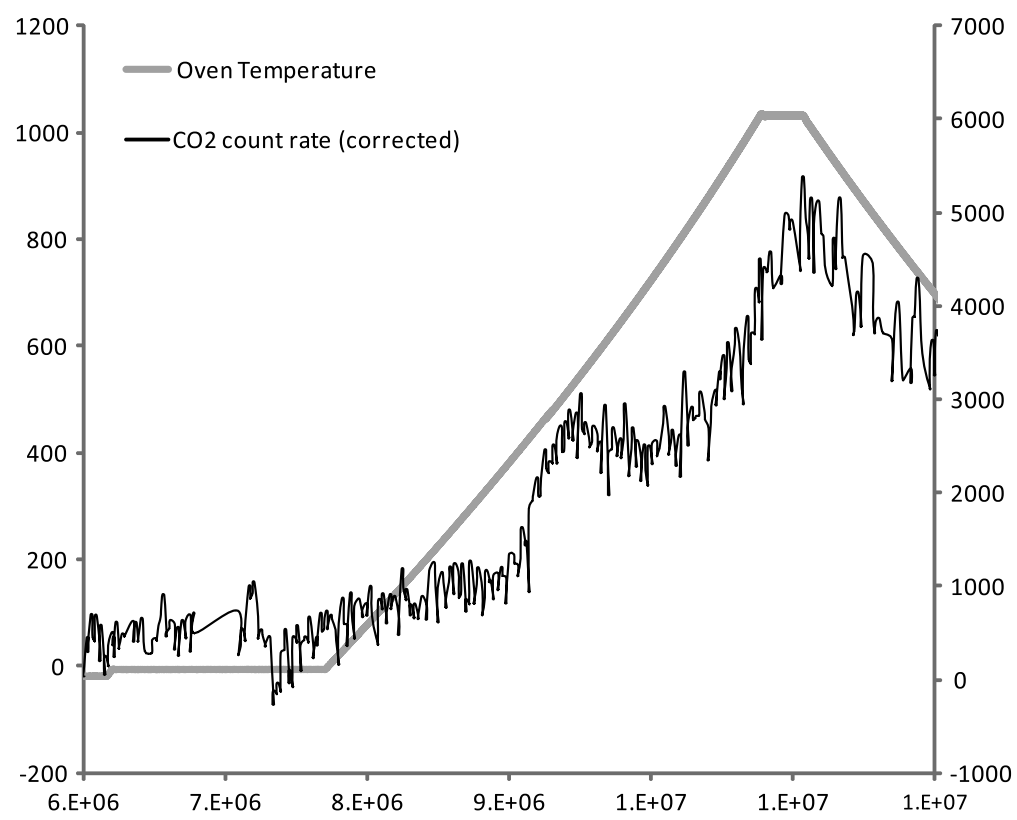

Fig. 8 Measurement of the Wicked Witch soil by TEGA after Boynton et al. (2009). The corrected count rate for $\mathrm{CO}_{2}$ is the mass 44 count rate measured during the analysis run corrected for background by subtraction of the mass 44 count rate measured during a reanalysis of the same sample on a subsequent day. Two $\mathrm{CO}_{2}$ peaks are apparent suggesting two separate releases of $\mathrm{CO}_{2}$. The higher temperature release has been interpreted to be from calcite by Boynton et al. (2009) and Sutter et al. (2012). The lower temperature release is less constrained and could be either an $\mathrm{Mg}-$, Fe-rich carbonate phase or possibly organic matter 
carbonate $(\sim 1.0$ wt.\% equivalent carbonate) or an organic material (Boynton et al. 2009; Sutter et al. 2012). One further possibility is that this lower temperature $\mathrm{CO}_{2}$ release was caused by reaction between carbonate and $\mathrm{HCl}$ formed during decomposition of $\mathrm{Mg}$ perchlorate (Cannon et al. 2012).

Several possibilities exist for the formation of the carbonates at the Phoenix landing site. They could have been derived from the Vastitas Borealis and Scandia deposition events, deposited as carbonate-bearing dust, and/or formed by pedogenic processes. The Phoenix landing site is situated on the ejecta from the Heimdall Crater (Heet et al. 2009) that might contain material from both the mid to late Hesperian Vastitas Borealis Formation (VBF) and the early Amazonian Scandia material which are both penetrated by Heimdall Crater (Salvatore et al. 2010; Tanaka et al. 2008). The VBF has been speculated to have formed from sediments generated by outflow channels during the Hesperian (Tanaka et al. 2011) and therefore might contain carbonate minerals eroded during those events or formed during the evaporation or freezing of the outflow channel effluents.

Another possibility is that the carbonates at the Phoenix landing site were originally derived from the Mg-carbonate bearing dust (2-5 wt.\%) (Bandfield et al. 2003) on Mars. Subsequent pedogenic processes could result in dissolution and reprecipitation of calcite and/or Ca-Mg carbonate (Sutter et al. 2012). This is a common reaction in soils overlying limestone where the dissolution of carbonate parent rock (e.g., limestone) is followed by reprecipitation of pedogenic carbonate (Rabenhorst et al. 1984).

Finally, the carbonate may have formed in-situ at the Phoenix landing site through interaction of atmospheric $\mathrm{CO}_{2}$ and ephemeral water films (Boynton et al. 2009). The presence of shallow subsurface ice in this location could provide thin films of water during diurnal and seasonal cycles (Smith et al. 2009a; Zent et al. 2010) which could provide conditions necessary for pedogenic carbonate formation. Obliquity variations may also have created conditions warm enough to melt subsurface ice and provide liquid water for pedogenic carbonate formation. Indeed, perchlorate salts (mainly of $\mathrm{Mg}$ form) are known to be present at the Phoenix site, and these allow brines to form at a eutectic temperature of about $-68{ }^{\circ} \mathrm{C}$ (Hecht et al. 2009).

The various hypotheses for the origin of Phoenix landing site carbonates suggest that such carbonates could be widespread across the northern plains and possibly beyond, although it is unclear whether they are confined to the upper few centimeters that were sampled by the Phoenix lander or if they are present at greater depths. Alkaline $\mathrm{pH}$ estimates (7.4-8.7) for the Viking soils based on the Viking Landers' gas exchange experiment (Quinn and Orenberg 1993) could suggest that soil carbonates may in fact be globally present at low enough levels to remain below the detection limits of the orbiting spectrometers.

\section{Models of Martian Carbonate Chemistry}

Martian carbonates have now been identified from orbit, on the surface, and in martian meteorites; yet the specific environmental conditions under which these carbonates formed remain relatively unconstrained. While specific constraints can be derived from martian meteorites through detailed chemical analysis, it is difficult to determine if these few samples reflect typical conditions elsewhere. Several studies have been conducted examining potential carbonate forming environments that span the range of climatic scenarios from warm/wet to cold and dry. Before the global mapping of mineralogy in the near and thermal infrared, models of martian aqueous chemistry entertained the possibility that carbonates might be globally widespread (Catling 1999), whereas subsequent models have now had to contend with explaining why carbonate outcrops are localized phenomena. 


\subsection{Warm/Wet Environments}

Pollack et al. (1987) predicted that carbonates would be abundant on the surface and would thus indicate the presence of an early dense $\mathrm{CO}_{2}$ atmosphere. Their model suggested that while $\mathrm{CO}_{2}$ would rapidly be removed by carbonate formation through weathering of basalt, a dense $\mathrm{CO}_{2}$ atmosphere ( 1 to 5 bars) could be maintained by constant recycling of $\mathrm{CO}_{2}$ back into the atmosphere through rapid burial and thermal decomposition of carbonate minerals. This envisioned a warm, wet Noachian environment with rainfall and standing bodies of water stabilized by a dense $\mathrm{CO}_{2}$ atmosphere.

This scenario along with others that depend on a dense early $\mathrm{CO}_{2}$ greenhouse have been challenged by climate models that cannot simulate warm enough conditions using a $\mathrm{CO}_{2}$ greenhouse as well as the localized nature and relative paucity of carbonates on the surface of Mars. In the early 1970s, Sagan and Mullen (1972) realized that the long-term increase in the luminosity of the Sun predicted by astrophysical theory would have consequences for the evolution of planetary climates and atmospheres. Specifically, over time, the Sun's core contracts and gets denser and hotter as hydrogen is fused into helium. A gradual increase in the temperature-sensitive nuclear fusion reactions has led to a rise in solar luminosity by 25-30 \% since 4 Ga (Bahcall et al. 2001; Gough 1981). So, if the widespread fluvial activity in the early and middle Noachian had been sustained by a warmer climate on early Mars, the early atmosphere must have been greatly different from today (Pollack et al. 1987).

Modeling a water vapor- $\mathrm{CO}_{2}$ greenhouse on early Mars has remained problematic. Initial calculations showed a water vapor- $\mathrm{CO}_{2}$ greenhouse effect in a 5 bar $\mathrm{CO}_{2}$ atmosphere would be sufficient to sustain liquid water on early Mars with solar luminosity $30 \%$ less than present (Pollack et al. 1987). However, a revision to the calculations indicated that $\mathrm{CO}_{2}$ ice clouds would start to condense out of the atmosphere at around $\sim 0.4$ bar surface pressure so that 5 bar surface pressure would not be attained (Kasting 1991). Subsequently, there was some debate about whether $\mathrm{CO}_{2}$ ice clouds themselves might have a net warming effect (Forget and Pierrehumbert 1997), but the most comprehensive calculations done to date show that the greenhouse effect from such clouds would, on average, be unable to warm the early martian surface above freezing (Colaprete and Toon 2003). The reasons are that $\mathrm{CO}_{2}$ cloud particles grow rapidly and precipitate, leading to fast cloud dissipation, while any warming is self-limiting because by heating the air, the clouds cause themselves to disappear. Other greenhouse gas candidates have been proposed along with alternative warming mechanisms (Haberle 1998). $\mathrm{A} \mathrm{pCO}_{2}$ of 1.5-2 bars coupled with $\sim 1 \%$ methane might globally warm early Mars above freezing (Kasting 1997). However, such levels of methane would require a methane source exceeding that of the modern terrestrial biosphere because methane is destroyed relatively rapidly in geologic time by ultraviolet photolysis and oxidation. Others have proposed that volcanic $\mathrm{SO}_{2}$, which is also a greenhouse gas, could have warmed Mars' early climate (Halevy et al. 2007; Johnson et al. 2008, 2009; Postawko and Kuhn 1986). However, the photochemistry of $\mathrm{SO}_{2}$ rapidly produces sulfate aerosols (even in reducing atmospheres), and sulfate aerosols reflect sunlight efficiently, producing a net global cooling (Tian et al. 2010). Nonetheless, warming due to $\mathrm{SO}_{2}$ production by volcanism or impact events may provide brief warming periods (Halevy and Head 2012; Johnson et al. 2009).

\subsection{Hydrothermal Environments}

Because the hypothesis of thick $\mathrm{CO}_{2}$ atmospheres on early Mars has various problems, a proposed alternative to a continuous warm, wet climate on early Mars is that much of the 
aqueous activity on Mars occurred in subsurface hydrothermal systems powered by magmatic or impact activity (Ehlmann et al. 2011; Griffith and Shock 1995; Newsom 1980; Squyres and Kasting 1994). On early Mars, several heat sources for near-surface hydrothermal systems would have existed, including secular planetary cooling (Parmentier and Zuber 2007), volcanism (Phillips et al. 2001; Werner 2009), and large impacts (Frey 2008; Werner 2008). In this scenario, much of the observed alteration to clay minerals (Ehlmann et al., this issue) and formation of thick sulfate deposits would have occurred in groundwater driven systems in a warmer subsurface with only transiently clement surface condition (Ehlmann et al. 2011).

While such systems do not produce the massive sedimentary carbonates once predicted for Mars (Pollack et al. 1987), carbonates may have formed easily in lower temperature subsurface hydrological systems, where they were protected from acidic, oxidizing surface environment. On Earth, hydrothermal systems in mafic rock types result in progressive alkalinization of the hydrothermal fluid; in ultramafic systems, serpentinization occurs, a process in which hydrogen gas and methane gas are produced by the alteration of olivine (Etiope et al. 2011).

A means of communication with the atmosphere or a carbon-rich magmatic fluid is required for carbonate formation at substantial depth in hydrothermal groundwater systems. On Earth, the mixing of the high-pH hydrothermal fluid derived from serpentinization with cold sea water is observed to produce calcite in submarine, ultramafic rock-hosted, carbonate mineral deposits precipitating at hydrothermal vents (Palandri and Reed 2004). Serpentinization of ultramafic rocks could convert crustal carbonate into $\mathrm{CH}_{4}$ through the reaction of dissolved $\mathrm{CO}_{2}$ with $\mathrm{H}_{2}$, similar to what is observed in hydrothermal systems of mid-ocean ridges (Atreya et al. 2007; Oze and Sharma 2005). Hydrothermal alteration of basaltic crust could produce $\mathrm{CH}_{4}$ and sequester $\mathrm{CO}_{2}$ in carbonates: the low intrinsic oxygen fugacity $\left(\mathrm{fO}_{2}\right)$ of martian basalt may force oxidized carbon supplied by magmatic degassing or crustal carbonates to reduce to $\mathrm{CH}_{4}$ during water-rock interaction (Lyons et al. 2005). Steele et al. (2007) argued that the carbonates in ALH 84001 formed under similar high temperature, low $\mathrm{fO}_{2}$ conditions resulting in the simultaneous formation of carbonates and macromolecular carbon.

Calculations using a shergottite-like host rock predict that a great majority of the precipitated carbonate would be in the form of calcite (Griffith and Shock 1995). During the progressive shrinking of the water table in the Hesperian and Amazonian, carbonate deposits may have migrated deeper into the crust, down to the present depth of the water table several kilometers below the surface (Chassefiere and Leblanc 2011a). If $2.5 \%$ carbonate formed and was dispersed throughout the upper $5 \mathrm{~km}$ of crust, this would result in the sequestration of 5 bars of $\mathrm{CO}_{2}$ (Griffith and Shock 1995). This is probably an upper bound for the carbonate content of the crust, but if globally distributed, even lower concentrations over a lesser depth constitute a substantial carbon reservoir, relative to the current 6 mbar atmosphere.

Evidence for this type of hydrothermal circulation may have recently been discovered by the detection of deep crustal carbonates from the spectral analysis of the central peak of the Leighton crater using CRISM data (Michalski and Niles 2010). The carbonates detected in this location alongside hydrated silicates very closely resemble the assemblage predicted by Griffith and Shock (1995). Mg-rich carbonates detected at Nili Fossae are also associated with hydrated silicates and may also have formed from hydrothermal activity (Brown et al. 2010; Ehlmann et al. 2008b; Gaudin et al. 2011). 


\subsection{Current Martian Conditions}

The current atmosphere of Mars is cold enough and at low enough pressure to be well below the triple point of water on average, indicating that liquid water is not stable at the surface (Richardson and Mischna 2005). However, several studies have suggested that transient liquid water may in fact be possible under the current martian climate (Hecht 2002; Ingersoll 1970; Kahn 1985) and there is evidence for the formation of small channels by some sort of liquid in the past few years (McEwen et al. 2011). Thus the current conditions on the martian surface may be sufficient to enable carbonate formation to be an active process on the surface today.

Kahn (1985) suggested that carbonate formation drew down the atmospheric pressure of $\mathrm{CO}_{2}$, thereby reducing temperatures and inhibiting liquid water and carbonate formation in negative feedback. In that case, the rate of $\mathrm{CO}_{2}$ sequestration would reach balance with the rate of outgassing. This hypothesis suggests that the current pressure of $\mathrm{CO}_{2}$ on Mars is regulated by ongoing carbonate formation and requires that carbonate formation be possible under the cold and dry conditions of the modern martian climate.

Several studies suggest that carbonate formation under modern martian conditions is possible and does indeed occur. Carbonates have been formed under simulated martian conditions in the laboratory (Booth and Kieffer 1978; Shaheen et al. 2010). The carbonate in fine dust could result from relatively dry conditions where several hundred monolayers of $\mathrm{H}_{2} \mathrm{O}$ around dust grains generate carbonate over geologic time. Laboratory experiments with basaltic fines have shown that carbonate can be produced with $10^{2}-10^{3}$ monolayers of water around particles in a $\mathrm{CO}_{2}$ atmosphere, which is equivalent to a moisture content of 0.1 to $0.5 \mathrm{~g} \mathrm{H}_{2} \mathrm{O}$ per g soil (Stephens 1995; Stephens et al. 1995). For comparison, the moisture content in unvegetated, high-altitude terrestrial soils below the snow line is $\sim 0.05 \mathrm{~g} / \mathrm{g}$ in the Peruvian Andes and $\sim 0.1 \mathrm{~g} / \mathrm{g}$ in the Colorado Rockies (King et al. 2008). On Mars, periodic "wet" conditions generated from melted ice over hundreds of millions of years might be responsible for the carbonates in the soil at the Phoenix landing site (Boynton et al. 2009). The existence of recent lava flows ( $\sim 2$ million years old) on Tharsis and Elysium (Neukum et al. 2004; Vaucher et al. 2009) shows that volcanism has been active in the near past (Grott et al. this volume), and Mars may still be internally active, with a potential for carbonate formation in volcanic hydrothermal systems at depth. Finally, many meteorites, both young and old, possess carbonates that have isotopic compositions consistent with formation in equilibrium from modern martian atmospheric $\mathrm{CO}_{2}$ (Niles et al. 2010) (Fig. 3).

\section{Discussion}

\section{1 $\mathrm{CO}_{2}$ Budget of Mars}

The atmosphere of Mars today is tenuous, consisting mainly of $\mathrm{CO}_{2}$ at a mean global pressure of about 6 mbar (Haberle et al. 2008). A previously unidentified deposit of solid $\mathrm{CO}_{2}$ was discovered by the Mars Reconnaissance Orbiter, in the form of bodies of $\mathrm{CO}_{2}$ ice embedded within the martian south polar layered deposits (Phillips et al. 2011) with an amount equivalent to a global pure $\mathrm{CO}_{2}$ atmospheric pressure of 4-5 mbar. More substantial amounts of $\mathrm{CO}_{2}$ could be adsorbed in the regolith, up to $\approx 140 \mathrm{mbar}$ (Fanale and Cannon 1979). $\mathrm{CO}_{2}$ may also be present in the martian cryosphere in the form of $\mathrm{CO}_{2}$ clathrate hydrates (Mousis et al., this issue), although in unknown amounts. The amount of $\mathrm{CO}_{2}$ contained in the identified atmospheric, polar and subsurface reservoirs under its molecular form is probably not in excess of a few tens or one hundred or so millibars. 
Like Venus and Earth, Mars should have been endowed with similar amounts of $\mathrm{CO}_{2}$ during main accretion (Owen and Bar-Nun 1995). Thermal escape of carbon is expected to have removed most of the primordial atmospheric $\mathrm{CO}_{2}$, with a characteristic time to lose 1 bar of $\mathrm{CO}_{2}$ in the range from 1 to $10 \mathrm{Myr}$ (Lammer et al., this issue). If most of Mars' atmospheric $\mathrm{CO}_{2}$ was emplaced during the main accretion phase, the entire inventory could have been lost within $40 \mathrm{Myr}$, ensuring that any primordial atmosphere was likely to have been removed (Tian et al. 2009). Following this loss to space of $\mathrm{CO}_{2}$, a secondary atmosphere progressively formed through volcanic outgassing of $\mathrm{CO}_{2}$ (Lammer et al., this issue). According to a morphological analysis of volcanic landforms on the surface, $0.3 \mathrm{bar}$ of $\mathrm{CO}_{2}$ would have been outgassed by volcanic eruptions during the last $4 \mathrm{Ga}$ (Craddock and Greeley 2009). Crustal production modeling suggests that a total $0.5-1$ bar of $\mathrm{CO}_{2}$ have been outgassed, mostly during the Noachian (Grott et al. 2011). Finally, modeling using $\mathrm{CO}_{2}$ contents of martian magmas based on the martian meteorites also predicts between 0 and 1.2 bars of $\mathrm{CO}_{2}$ outgassing in the past $4.5 \mathrm{Ga}$ (Stanley et al. 2011). Thus, up to $\sim 1.2$ bar of magmatic $\mathrm{CO}_{2}$ has been released to the atmosphere throughout martian history. Recycling of $\mathrm{CO}_{2}$ from ancient carbonate deposits could allow for higher year to year average outgassing rates, but would not impact the overall inventory available at the surface (Pollack et al. 1987).

Using up-to-date values of Mars' C non-thermal escape rates, no more than 200 mbar of $\mathrm{CO}_{2}$ may have been removed by escape during the last $4 \mathrm{Ga}$ (Lammer et al. this issue). The recent measurement of the isotopes of the martian atmospheric $\mathrm{CO}_{2}$ by the Phoenix mission (Niles et al. 2010) clearly shows that escape has not played an important role in fractionating $\mathrm{CO}_{2}$ during the last $4 \mathrm{Ga}$, in agreement with most recent model calculations (Chassefiere and Leblanc 2011b). A primitive ${ }^{13} \mathrm{C}$ enrichment possibly due to early sputtering and hydrodynamic escape, would have been later erased through both longterm carbonate formation and dilution from mantle outgassed $\mathrm{CO}_{2}$ (Gillmann et al. 2011; Niles et al. 2010). The SAM instrument on the MSL mission is poised to potentially make isotopic measurements of Hesperian carbonates (if present) at Gale crater which could further our understanding of the atmospheric evolution of Mars. Furthermore, measurements made by the MAVEN spacecraft will provide stronger constraints on the non-thermal escape of $\mathrm{CO}_{2}$ from Mars as well as the isotopic fractionation associated with that process.

Removal of the atmosphere through blow off during large impacts is also a possibility and could be important during the early Noachian (Brain and Jakosky 1998; Manning et al. 2006; Melosh and Vickery 1989; Newman et al. 1999). Impact erosion would have removed $\mathrm{CO}_{2}$ and other gases en masse and would not create isotopic fractionation unlike non-thermal escape processes (Melosh and Vickery 1989). Impact erosion may have removed much of the early volcanically-released $\mathrm{CO}_{2}$ during the Noachian, but its importance relative to EUV-powered escape processes may be small if EUV-powered processes removed the protoatmosphere in $10 \mathrm{Myr}$ (Lammer et al. this issue). Thus any carbonates are likely the product of a secondary atmosphere.

Estimates of the total amount of $\mathrm{CO}_{2}$ deposited as carbonate on the martian surface remain relatively unconstrained. A useful benchmark for making this estimation is that 1 bar of $\mathrm{CO}_{2}$ can create the equivalent of a planet-wide cover of $\sim 20 \mathrm{~m}$ of pure calcite on the surface of Mars. This is calculated using depth $=\left(P_{\mathrm{s}} M_{\mathrm{CaCO} 3}\right) /\left(g M_{\mathrm{CO} 2} \rho_{\mathrm{CaCO} 3}\right)$, where a surface pressure of $1 \mathrm{bar}$ is $P_{\mathrm{s}}=10^{5} \mathrm{~Pa}$, the molar mass of carbon dioxide is $M_{\mathrm{CO} 2}=0.044 \mathrm{~kg} \mathrm{~mol}^{-1}$, the molar mass of calcite $M_{\mathrm{CaCO} 3}=0.1 \mathrm{~kg} \mathrm{~mol}^{-1}$, the density of calcite is $\rho_{\mathrm{CaCO} 3}=2710 \mathrm{~kg} \mathrm{~m}^{-3}$, and $g$ is the gravitational acceleration on Mars. Ultimately this type of calculation needs to be constrained by accurate estimates of the carbonate content of the martian crust which currently don't exist. 
One possible method for estimating the size of the global carbonate reservoir is by using the carbonate in the global dust (Bandfield et al. 2003). It is possible that carbonates exposed at the surface and deep carbonates exposed by impact could be the source of carbonates observed in the martian dust (Bandfield et al. 2003; Ehlmann et al. 2008b) especially if the dust on Mars formed primarily due to pulverization of the upper crust of Mars by impact processes. Thus, if the (2-5\%) carbonate detected in the global dust represented the average composition of the upper 1-3 km of the crust of Mars, it is possible that 1-3 bars of $\mathrm{CO}_{2}$ are sequestered on the surface (Bandfield et al. 2003). The presence of carbonates in the Phoenix soils might support this claim somewhat by showing that the carbonates are not restricted to the fine grained dust and may be globally present in the martian soils as well (see Sect. 4.2 above). However, the depth in the crust at which carbonates are present remains a major uncertainty in this kind of estimate. The extrapolation of the weight abundance of carbonate in the dust downwards through the subsurface bedrock has no justification considering the low carbonate abundances measured in meteorites which are our only samples of the near surface crust of Mars. Assuming $~ 0.5$ wt.\% carbonate (i.e., an assumption weighted towards the higher carbonate abundance in ALH84001), an extrapolation through $1 \mathrm{~km}$ of the subsurface would give an upper bound of no more than 0.25 bar of sequestered $\mathrm{CO}_{2}$. Furthermore recent studies (see Sect. 5.3 above) have shown that carbonate may be forming in the modern environment of Mars, making it likely that the proportion of carbonate in the dust and soil has been substantially elevated by Amazonian weathering and is therefore not representative of carbonate deposits at depth.

Another method for assessing the inventory of carbonates on Mars is through observations from orbital data which show that carbonates are not as abundant and widespread as was once anticipated and are not as abundant and widespread as other alteration minerals on Mars such as phyllosilicates, chlorides, and sulfates, although lack of exposure may lead to underestimations of the abundance of all of these phases within ancient rocks as described in Sect. 5.1 above. Carbonate rocks on Earth are prominent on the surface due to the dominance of shelf carbonates in the sedimentary record, which display regional stratigraphic continuity, can be very thick, and contain abundant carbonate minerals, usually calciumrich. Perhaps a similar situation was once expected for Mars (Fanale and Cannon 1974; Fanale et al. 1982; Pollack et al. 1987), but orbital data do not support this hypothesis. Instead, remote sensing data have revealed that $\mathrm{Mg}$-carbonates are more typical, and that these deposits are relatively rare and possibly related to local weathering and alteration processes.

If Mars hosted a dense $\mathrm{CO}_{2}$ atmosphere ( $>1$ bar) in the Noachian, large ( $>20 \mathrm{~m}$ global equivalent layer of calcite) carbonate deposits should have been formed during or after the Noachian/Hesperian transition. Based on the current observations summarized above (Sects. 3 and 4), Hesperian carbonate outcrops of any size have not been detected thus far. Of course it is possible that these Hesperian carbonates are simply hidden from view since much of the martian surface is obscured by dust (Ruff and Christensen 2002) that can't be penetrated by the NIR or TIR spectrometers although that has not posed a problem for detections of other alteration minerals such as sulfates, phyllosilicates and clays.

We are limited to observations in areas where the geology is well-exposed and detectable using the available instruments, thus several possibilities exist for "hidden" carbonates on Mars (Craddock and Howard 2002). First of all, the terrain around Nili Fossae is perhaps the best example of well-exposed, ancient terrain on Mars and it might imply that carbonates could also be present in additional buried Noachian units. Hesperian and Amazonian units do not exhibit evidence for carbonates and might indicate that the atmosphere was sparse as far back as the late Noachian. A possibility is that later acidity might have decomposed or prevented Hesperian and Amazonian carbonates from forming (Bibring et al. 2006; 
Bullock and Moore 2007; Fairen et al. 2004) but this dissolution process would simply return the $\mathrm{CO}_{2}$ to the atmosphere where it would have to be reprecipitated as carbonate somewhere else at a later time (see Sect. 6.3 below). Another possibility is that volcanism in the Amazonian might end up producing a sulfate rind on carbonate outcrops through heterogeneous (gas-solid) reactions that turn carbonates into sulfates (Clark and Baird 1979) thus obscuring the carbonate from detection. It may also be possible that the carbonates are widely dispersed and in low enough abundance so that they cannot be detected using the available instrumentation (Blaney and McCord 1989). Finally, micro-roughness common to surfaces of caliche and travertine on Earth reduce spectral contrast of carbonate minerals, potentially masking carbonate detection in the thermal infrared (Kirkland et al. 2002), although this effect has not been shown to be applicable to VNIR spectra.

Because the hypothesis of a thick $\mathrm{CO}_{2}$ atmosphere on early Mars has various problems, it is possible that the $\mathrm{CO}_{2}$ budget of Mars has been relatively small. Presuming that the proto-atmosphere and earliest pre-Noachian atmospheres were rapidly lost due to the high solar EUV flux and impact erosion (Lammer et al. this issue), carbonate formation may have been restricted to the earliest periods in martian history. If the subsequent volcanic outgassing and growth of a secondary atmosphere remained small, then the overall amount of $\mathrm{CO}_{2}$ available for carbonate formation during the Noachian, Hesperian, and Amazonian may have been quite limited (Grott et al. 2011; Manning et al. 2006). Thus the climate of Mars could have been similar to the modern martian climate throughout history (Gaidos and Marion 2003). Another possibility is that there have been a series of intermittent warm, wet episodes caused by heat dumped by very large impacts (Segura and Navarro-Gonzalez 2005; Segura et al. 2002; Toon et al. 2010). In this hypothesis, a temporary greenhouse effect does not rely upon large quantities of $\mathrm{CO}_{2}$, which has the virtue of being consistent with a general lack of carbonate outcrops. This would result in a series of transient aqueous episodes that temporarily mobilized liquid water on the surface followed by evaporation or sublimation. Other models for intermittent warm periods are those supported by massive volcanic eruptions of $\mathrm{CO}_{2}$ e.g. (Phillips et al. 2001) and would also have to account for the lack of Hesperian and Amazonian carbonate outcrops on the martian surface.

\subsection{Chemistry-Mg-, Fe-rich vs. Ca-, Fe-rich}

The wide ranging chemistry of the martian carbonates is in contrast to carbonate chemistry on Earth, which is dominated by Ca-rich phases: calcite, aragonite and dolomite. This could be due to differences in fluid chemistry, but may also be due to differences in carbonate mineral formation environments. Ca-rich phases dominate in terrestrial environments despite the fact that the oceans are Mg-rich, thus the differences in carbonate chemistry between Mars and Earth may be due to the fundamental differences in the aqueous environments on the two planets.

The prevalence of magnesite-rich carbonates on Mars suggests that conditions for magnesite formation may give clues to early martian environments. Primary, anhydrous magnesite is difficult to form as a direct precipitate from a low temperature standing body of water, in contrast to calcite. The reason is that the $\mathrm{Mg}^{2+}$ ion in solution is strongly hydrated, so that for the $\mathrm{Mg}^{2+}$ ion to enter into the magnesite crystal without bound water requires energy, which presents a "dehydration barrier" (Lippmann 1973). Consequently, hydrates of magnesium carbonate and hydroxyhydrates are the common precipitates from aqueous solution, whereas primary magnesite is absent from marine evaporites. Specifically, the forms of magnesite that are favored with increasing temperature are lansfordite $\left(\mathrm{MgCO}_{3} \cdot 5 \mathrm{H}_{2} \mathrm{O}\right)$, nesquehonite $\left(\mathrm{MgCO}_{3} \cdot 3 \mathrm{H}_{2} \mathrm{O}\right)$ and hydromagne- 
site $\left(\mathrm{Mg}_{5}\left(\mathrm{CO}_{3}\right)_{4}(\mathrm{OH})_{2} \cdot 4 \mathrm{H}_{2} \mathrm{O}\right.$ or $\left.\mathrm{Mg}_{4}\left(\mathrm{CO}_{3}\right)_{3}(\mathrm{OH})_{2} \cdot 3 \mathrm{H}_{2} \mathrm{O}\right)$. Such hydrous magnesites often form as the result of the hydrothermal alteration of $\mathrm{Mg}$-rich basic igneous rocks or of serpentinites that were, in turn, originally formed by hydrothermal activity (Pohl 1989; Russell 1996). Ignoring the hydration state for simplicity, carbonation of Mg-olivine (forsterite) proceeds schematically as follows:

$$
4 \mathrm{Mg}_{2} \mathrm{SiO}_{4}+4 \mathrm{H}_{2} \mathrm{O}+2 \mathrm{CO}_{2}=2 \mathrm{Mg}_{3} \mathrm{Si}_{2} \mathrm{O}_{5}(\mathrm{OH})_{4(\text { serpentine) }}+2 \mathrm{MgCO}_{3 \text { (magnesite) }}
$$

Hydrothermal alteration of serpentine into magnesite is seen in the vein swarms of the Piedmont magnesite deposit in the Great Serpentine Belt of New South Wales, Australia (Brownlow and Ashley 1991). Hydromagnesite occurrences where groundwater is in contact with basic igneous rocks and flows into lakes include the carbonate lakes of British Columbia, Canada, the Coorongs of S. Australia, and the East African Rift Valley. A further example is in the highly Mg-rich, alkaline ( $\mathrm{pH}>9$ ) waters of Salda Lake, Turkey, where lake drainage is rimmed on three sides by serpentinites (Russell et al. 1999).

Given the difficulties in forming anhydrous magnesite, it is puzzling as to why it occurs instead of more Ca-rich varieties in ALH 84001 (Mittlefehldt 1994). On Earth and in laboratory experiments magnesite typically indicates elevated temperatures (Lippmann 1973), however the accumulated observations of the ALH 84001 carbonates suggests a low temperature origin. Anhydrous magnesite can also form under conditions of reduced activity of water such as evaporative environments (Canaveras et al. 1998; Pohl 1989). The ALH84001 carbonates have been proposed to form as evaporative precipitates of rapidly receding floodwaters or in a playa lake environment analogous to some low temperature terrestrial environments that host Mg-rich carbonates (McSween and Harvey 1998; Warren 1998).

Unlike the Mg-rich carbonates in nearby Nili Fossae and elsewhere, those excavated from the deep crust in Leighton crater have spectral signatures of siderite $\left(\mathrm{FeCO}_{3}\right)$ or possibly calcite $\left(\mathrm{CaCO}_{3}\right)$ (Michalski and Niles 2010). Siderite is typical of a carbonate deposited in anoxic conditions under a moderate $\mathrm{pCO}_{2}$ (Catling 1999), although the exact $\mathrm{pCO}_{2}$ required is subject to some uncertainty. One way to set a limit on the $\mathrm{pCO}_{2}$ is to consider the equilibrium between siderite and hydrous iron silicates, where the latter would form at lower $\mathrm{pCO}_{2}$ instead of siderite. For example, a precursor to hydrous iron silicates such as greenalite or minnesotaite, which are found after diagenesis and burial, is berthierine $\left(\mathrm{Fe}_{2} \mathrm{Al}_{2} \mathrm{SiO}_{5}(\mathrm{OH})_{4}\right)$. One can consider the equilibrium between berthierine, siderite and kaolinite $\left(\mathrm{Al}_{2} \mathrm{Si}_{2} \mathrm{O}_{5}(\mathrm{OH})_{4}\right)$, as follows:

$$
\mathrm{Fe}_{2} \mathrm{Al}_{2} \mathrm{SiO}_{5}(\mathrm{OH})_{4}(\mathrm{~s})+\mathrm{SiO}_{2}(\mathrm{aq})+2 \mathrm{CO}_{2}(\mathrm{~g})=2 \mathrm{FeCO}_{3}(\mathrm{~s})+\mathrm{Al}_{2} \mathrm{Si}_{2} \mathrm{O}_{5}(\mathrm{OH})_{4}(\mathrm{~s})
$$

Depending on the assumed activity of aqueous silica-perhaps close to saturation-a thermodynamic estimate of the $\mathrm{pCO}_{2}$ can be calculated (Sheldon 2006). Similar estimates can also be made for the equilibria of siderite with other phyllosilicates (Chevrier et al. 2007). The result is that the $\mathrm{pCO}_{2}$ boundary between siderite and typical phyllosilicates lies around 1-10 mbar. Thus, the presence of siderite on Mars only suggests $\mathrm{pCO}_{2}$ values somewhat higher than today's mean atmospheric $\mathrm{pCO}_{2}$ or comparable to it, while the formation of certain phyllosilicates would require isolation from a thick carbon dioxide atmosphere, such as in the subsurface. Carbonates excavated from the deep crust may provide a glimpse of a vast record of very ancient, deeply buried sedimentary carbonates from a warmer climate, but a simpler explanation might be local ancient subsurface hydrothermal alteration. Either way, the presence of ferrous iron $\left(\mathrm{Fe}^{2+}\right)$ in siderite implies a reducing environment, unlike the modern oxidizing atmosphere on Mars. 


\subsection{Acid vs. Alkaline}

The detection of carbonates in Mars rocks and soils has indicated that mildly alkaline geochemical conditions on Mars have existed throughout most of martian history (see Sects. 3.1 and 4.2 above). Acidic mineralogy has been detected on Mars (Farrand et al. 2009; Knoll et al. 2005; Morris et al. 2006; Yen et al. 2008) and has been proposed to indicate that acidic geochemistry has dominated Mars for the past $3.5 \mathrm{Ga}$, while neutral to alkaline environments were more common earlier during widespread formation of phyllosilicates (Bibring et al. 2006; Hurowitz and McLennan 2007). However, the coexistence of both acidic and alkaline environments on Mars suggests that solution $\mathrm{pH}$ has likely been heterogeneous throughout the geologic history of Mars and likely depends on the local environment.

It has been proposed that a global acidic environment dominated by sulfate deposition in the Hesperian (Bibring et al. 2006) could explain the lack of carbonates from that era. Indeed, based on the abundance and character of sulfur on Mars, it is possible that it has played the same role as carbon plays in the weathering process on the Earth (Halevy et al. 2007). Among the possible acidic gases of geological origin, $\mathrm{SO}_{3}$ is the most soluble and has the lowest acidity constant, its aqueous form being sulfuric acid. It also produces sulfate by reaction with silicate rocks. However, magmatic degassing releases different forms of sulfur such as $\mathrm{H}_{2} \mathrm{~S}$, native sulfur or $\mathrm{SO}_{2}$, but not $\mathrm{SO}_{3}$, although the latter forms in atmospheric chemistry and hydrates into $\mathrm{H}_{2} \mathrm{SO}_{4}$ aerosols (Gaillard et al., this issue). Thus one potential way to reconcile the absence of Hesperian aged carbonate outcrops with an early thick $\mathrm{CO}_{2}$ atmosphere is that sulfuric or sulfurous acids in large, standing bodies of water on early Mars suppressed the formation of carbonates or dissolved existing carbonates (Fairen et al. 2004; Halevy et al. 2007). The dissolution and instability of carbonates in acid is well known and occurs at $\mathrm{pH}<6.2$ at $\mathrm{pCO}_{2}$ of 1 bar and $\mathrm{pH}<7.7$ at a $\mathrm{pCO}_{2}$ of 10 mbar (Bullock and Moore 2007). However, while carbonate precipitation may have been suppressed in the Hesperian by widespread acidic conditions this does not provide an explanation for where the atmospheric $\mathrm{CO}_{2}$ from this time period has gone.

Another problem with the acidic Hesperian hypothesis is that, over time, weathering fluids within a fractured basaltic regolith will tend to neutralize acid, deposit salts, and become alkaline. Mafic or ultramafic materials consume hydrogen ions and end up buffering standing bodies of water at an alkaline $\mathrm{pH}$ at moderate temperatures. For example, despite a continuous addition of acid volatiles from volcanism, the terrestrial ocean maintains a $\mathrm{pH}$ of $\sim 8$ because it is buffered by the chemistry of a basaltic seafloor (Macleod et al. 1994). The silicate minerals of basalt are effectively salts of weak acids and strong bases, so that when they dissolve in water the result is a weakly alkaline solution (Stevens and Carron 1948). Pulverized basalt added to water at room temperature produces a pH of roughly 9-10. Finally, in context with the widespread clay minerals on Mars (Ehlmann et al., this issue), widespread acidic solutions are unlikely. Clay minerals, such as smectite, have exchangeable cations in the interlayer position of the structure, conferring swelling properties and large sorption capacity making the clays an ionic exchanger. In contact with an acidic solution, $\mathrm{H}+$ exchange with the compensating cations and clays is a well known and efficient alkaline $\mathrm{pH}$ buffer. Several studies (Baldridge et al. 2009; Chevrier et al. 2004; Hurowitz et al. 2010; Zolotov and Shock 2005) have proposed potential mechanisms for creating acidic solutions on Mars revolving around weathering of sulfide minerals and oxidation of reduced iron. This is a viable alternative to forming sulfates from atmospheric $\mathrm{SO}_{2}$ but suggests that sulfate deposits on Mars should be enriched in iron as well as sulfur.

Another possible explanation for the acid-alkaline problem revolves around low-water rock ratios which limit the amount of interaction with the basaltic crust and allow for the 
coexistence of alkaline and acidic micro-environments in direct proximity (Berger et al. 2009; Niles and Michalski 2009). Low water-rock conditions are also consistent with a cold thin atmosphere which contains minimal amounts of $\mathrm{CO}_{2}$. This type of environment could allow for local regions of acidic and alkaline alteration and even possibly alternating acidic and alkaline conditions in the same location as may be indicated by the interbedded sulfates and phyllosilicates at Gale crater (Milliken et al. 2010).

\section{Summary and Conclusions}

The collection of martian carbonates discovered to date does not rule out the possibility of a dense Noachian $\mathrm{CO}_{2}$ atmosphere but nonetheless does not support it. The Nili Fossae, Leighton crater, and Gusev crater carbonates (Sects. 3.2 and 4.1) are all likely formed during the Noachian time period, and some could potentially have formed earlier. They all represent mixtures of carbonates with igneous minerals, suggesting formation via rock alteration by subsurface fluids rather than sedimentary precipitation. The carbonates in ALH 84001 and the nakhlites (Changela and Bridges 2011; Valley et al. 1997) were also likely formed during brief aqueous events in the subsurface. Taken together, these carbonates are evidence for the presence of subsurface water as opposed to surficial bodies of water, and they likely pre-date the formation of the valley networks and the Noachian-Hesperian transition when the dense $\mathrm{CO}_{2}$ atmosphere was supposed to have been lost (Carr and Head 2010; Fassett and Head 2008, 2011). The carbonates discovered in the dust (Sect. 3.1) and the martian soils (Sect. 4.2) could represent a much larger crustal reservoir derived from a dense early atmosphere. It is very likely that the carbonate in the dust may be the result of Amazonian weathering processes that have enriched the topmost dust and soils with small amounts of carbonate.

The carbonate record summarized in this review supports a martian aqueous history that is much more limited than what has previously been proposed. Instead of lakes and oceans, we have evidence for carbonate formation from subsurface fluids in the Noachian that declined and transitioned to formation from limited amounts of water in the Hesperian and Amazonian. In many cases the Mg-rich nature of the carbonates suggests low activity of water, which might be due to evaporation or cryo-concentration consistent with an arid environment. While it is clear that acidic conditions were important on Mars, the mineralogic composition of the crust suggests that acidity was limited to local environments or was present under very low water-rock conditions. This more limited view does not require dense $\mathrm{CO}_{2}$ Noachian atmospheres with the associated abundant Hesperian carbonate deposits but does allow for localized regions of hydrothermal activity occurring in the subsurface volcanic rocks.

While the global view of martian aqueous history presented here may not be ideal with regard to habitability as understood from study of Earth organisms, the longevity of the localized subsurface aqueous activity is poorly constrained and some locales might in fact represent highly desirable astrobiological destinations. The co-occurrence of hydrated phyllosilicates and carbonate minerals in Nili Fossae and Leighton crater in particular, provide strong candidates for the investigation of the habitability of Mars. These sites west of the Isidis basin show strong evidence for the prolonged past presence of liquid water, the presence of carbon, and the presence of heat which are all critical prerequisites for the possible existence of life.

Based on the work presented here, it is possible that the Mars Science Laboratory rover will encounter carbonates at the Gale crater landing site and in the Gale crater sediments. 
Carbonate is expected to be present in low concentrations in the dust and soils similar to what was found at the Phoenix landing site and observed from orbit. This could also be true for the sediments in the Gale crater mound. Carbonate minerals may also be present at Gale in association with mafic materials in volcaniclastic materials similar to the carbonates at Gusev crater and what may be present at Nili Fossae. Discoveries of Hesperian-aged carbonate beds or lenses at Gale crater would be unexpected based on the observations described in this review and would provide a compelling counter argument to the interpretation of Mars aqueous history presented here.

Acknowledgements Thoughtful reviews were provided by Ralph Harvey and Jim Bell which greatly improved the manuscript. Thanks to M. Toplis and the ISSI conference organizers for coordinating this review and promoting interesting discussions. E. Chassefière acknowledges support from CNRS EPOV interdisciplinary program.

\section{References}

L.M. Anovitz, E.J. Essene, J. Pet. 28, 389-414 (1987)

S.K. Atreya, P.R. Mahaffy, A.-S. Wong, Planet. Space Sci. 55, 358-369 (2007)

J.N. Bahcall, M.H. Pinsonneault, B. Sarbani, Astrophys. J. 555, 990 (2001)

A.M. Baldridge, S.J. Hook, J.K. Crowley, G.M. Marion, J.S. Kargel, J.L. Michalski, B.J. Thomson, C.R. de Souza, N.T. Bridges, A.J. Brown, Geophys. Res. Lett. 36 (2009)

J.L. Bandfield, T.D. Glotch, P.R. Christensen, Science 301, 1084-1087 (2003)

G. Berger, M.J. Toplis, E. Treguier, C. d'Uston, P. Pinet, Am. Mineral. 94, 1279-1282 (2009)

J.P. Bibring, Y. Langevin, J.F. Mustard, F. Poulet, R. Arvidson, A. Gendrin, B. Gondet, N. Mangold, P. Pinet, F. Forget, The OMEGA team, M. Berthe, J.-P. Bibring, A. Gendrin, C. Gomez, B. Gondet, D. Jouglet, F. Poulet, A. Soufflot, M. Vincendon, M. Combes, P. Drossart, T. Encrenaz, T. Fouchet, R. Merchiorri, G. Belluci, F. Altieri, V. Formisano, F. Capaccioni, P. Cerroni, A. Coradini, S. Fonti, O. Korablev, V. Kottsov, N. Ignatiev, V. Moroz, D. Titov, L. Zasova, D. Loiseau, N. Mangold, P. Pinet, S. Doute, B. Schmitt, C. Sotin, E. Hauber, H. Hoffmann, R. Jaumann, U. Keller, R. Arvidson, J.F. Mustard, T. Duxbury, F. Forget, G. Neukum, Science 312, 400-404 (2006)

D.L. Blaney, T.B. McCord, J. Geophys. Res. 94, 10159-10166 (1989)

D.D. Bogard, J. Park, Meteorit. Planet. Sci. 43, 1113-1126 (2008)

M.C. Booth, H.H. Kieffer, J. Geophys. Res. 83, 1809-1815 (1978)

A. Bouvier, J. Blichert-Toft, J.D. Vervoort, P. Gillet, F. Albarède, Earth Planet. Sci. Lett. 266, 105-124 (2008)

W.V. Boynton, D.W. Ming, S.P. Kounaves, S.M.M. Young, R.E. Arvidson, M.H. Hecht, J. Hoffman, P.B. Niles, D.K. Hamara, R.C. Quinn, P.H. Smith, B. Sutter, D.C. Catling, R.V. Morris, Science 325, 61-64 (2009)

D.A. Brain, B.M. Jakosky, J. Geophys. Res. 103, 22689-22694 (1998)

J.C. Bridges, M.M. Grady, Earth Planet. Sci. Lett. 176, 267-279 (2000)

J.C. Bridges, P.H. Warren, J. Geol. Soc. 163, 229-251 (2006)

J.C. Bridges, D.C. Catling, J.M. Saxton, T.D. Swindle, I.C. Lyon, M.M. Grady, Space Sci. Rev. 96, 365-392 (2001)

A.J. Brown, S.J. Hook, A.M. Baldridge, J.K. Crowley, N.T. Bridges, B.J. Thomson, G.M. Marion, C.R. de Souza Filho, J.L. Bishop, Earth Planet. Sci. Lett. 297, 174-182 (2010)

J.W. Brownlow, P.M. Ashley, Q. Notes, Geol. Surv. New South Wales 82, 1-20 (1991)

M.A. Bullock, J.M. Moore, Geophys. Res. Lett. 34, L19201 (2007)

W.M. Calvin, T.V.V. King, R.N. Clark, J. Geophys. Res. 99, 14659-14675 (1994)

J.C. Canaveras, M.S. Sanchez, R.E. Sanz, M. Hoyos, Sediment. Geol. 119, 183-194 (1998)

K.M. Cannon, B. Sutter, D.W. Ming, W.V. Boynton, R. Quinn, Geophys. Res. Lett. 39, L13203 (2012)

M.H. Carr, J.W. Head, Earth Planet. Sci. Lett. 294, 185-203 (2010)

J. Carter, F. Poulet, Icarus 219, 250-253 (2012)

D.C. Catling, J. Geophys. Res. 104, 16453-16469 (1999)

H.G. Changela, J.C. Bridges, Meteorit. Planet. Sci. 45, 1847-1867 (2011)

E. Chassefiere, F. Leblanc, Earth Planet. Sci. Lett. 310, 262-271 (2011a)

E. Chassefiere, F. Leblanc, Planet. Space Sci. 59, 207-217 (2011b)

V. Chevrier, P. Rochette, P.-E. Mathé, O. Grauby, Geology 32, 1033-1036 (2004)

V. Chevrier, F. Poulet, J.-P. Bibring, Nature 448, 60-63 (2007) 
P.R. Christensen, J.L. Bandfield, V.E. Hamilton, S.W. Ruff, H.H. Kieffer, T.N. Titus, M.C. Malin, R.V. Morris, M.D. Lane, R.L. Clark, B.M. Jakosky, M.T. Mellon, J.C. Pearl, B.J. Conrath, M.D. Smith, R.T. Clancy, R.O. Kuzmin, T. Roush, G.L. Mehall, N. Gorelick, K. Bender, K. Murray, S. Dason, E. Greene, S. Silverman, M. Greenfield, J. Geophys. Res. 106, 23823-23871 (2001)

P.R. Christensen, M.B. Wyatt, T.D. Glotch, A.D. Rogers, S. Anwar, R.E. Arvidson, J.L. Bandfield, D.L. Blaney, C. Budney, W.M. Calvin, A. Faracaro, R.L. Fergason, N. Gorelick, T.G. Graff, V.E. Hamilton, A.G. Hayes, J.R. Johnson, A.T. Knudson, H.Y. McSween, G.L. Mehall, L.K. Mehall, J.E. Moersch, R.V. Morris, M.D. Smith, S.W. Squyres, S.W. Ruff, M.J. Wolff, Science 306, 1733-1739 (2004)

M.J. Cintala, R.A.F. Grieve, Meteorit. Planet. Sci. 33, 889-912 (1998)

B.C. Clark, A.K. Baird, J. Geophys. Res. 84, 8395-8403 (1979)

A. Colaprete, O.B. Toon, J. Geophys. Res. 108, 5025 (2003)

C.M. Corrigan, R.P. Harvey, Meteorit. Planet. Sci. 39, 17-30 (2004)

R.A. Craddock, R. Greeley, Icarus 204, 512-526 (2009)

R.A. Craddock, A.D. Howard, J. Geophys. Res. 107 (2002)

B.L. Ehlmann, J.F. Mustard, C.I. Fassett, S.C. Schon, J.W. Head, D.J.D. Marais, J.A. Grant, S.L. Murchie, Nat. Geosci. 1, 355-358 (2008a)

B.L. Ehlmann, J.F. Mustard, S.L. Murchie, F. Poulet, J.L. Bishop, A.J. Brown, W.M. Calvin, R.N. Clark, D.J. Des Marais, R.E. Milliken, L.H. Roach, T.L. Roush, G.A. Swayze, J.J. Wrray, Science 322, 1828-1832 (2008b)

B.L. Ehlmann, J.F. Mustard, G.A. Swayze, R.N. Clark, J.L. Bishop, F. Poulet, D.J. Des Marais, L.H. Roach, R.E. Milliken, J.J. Wray, O. Barnouin-Jha, S.L. Murchie, J. Geophys. Res. 114 (2009)

B.L. Ehlmann, J.F. Mustard, S.L. Murchie, J.-P. Bibring, A. Meunier, A.A. Fraeman, Y. Langevin, Nature 479, 53-60 (2011)

J.M. Eiler, J.W. Valley, C.M. Graham, J. Fournelle, Geochim. Cosmochim. Acta 66, 1285-1303 (2002)

G. Etiope, M. Schoell, H. Hosgorrmez, Earth Planet. Sci. Lett. 310, 96-104 (2011)

A.G. Fairen, D. Fernandez-Remolar, J.M. Dohm, V.R. Baker, R. Amils, Nature 431, 423-426 (2004)

F.P. Fanale, W.A. Cannon, J. Geophys. Res. 79, 3397-3402 (1974)

F.P. Fanale, W.A. Cannon, J. Geophys. Res. 84, 8404-8414 (1979)

F.P. Fanale, J.R. Salvail, W. Bruce Banerdt, R.S. Saunders, Icarus 50, 381-407 (1982)

J. Farquhar, M.H. Thiemens, J. Geophys. Res. 105, 11991-11997 (2000)

J. Farquhar, M.H. Thiemens, T. Jackson, Science 280, 1580-1582 (1998)

W.H. Farrand, T.D. Glotch, J.W. Rice Jr, J.A. Hurowitz, G.A. Swayze, Icarus 204, 478-488 (2009)

C.I. Fassett, J.W. Head, Icarus 195, 61-89 (2008)

C.I. Fassett, J.W. Head, Icarus 211, 1204-1214 (2011)

F. Forget, R.T. Pierrehumbert, Science 278, 1273-1276 (1997)

H.V. Frey, J. Geophys. Res. 111 (2006)

H. Frey, Geophys. Res. Lett. 35, L13203 (2008)

S.J. Gaffey, J. Geophys. Res. 92, 1429-1440 (1987)

E. Gaidos, G. Marion, J. Geophys. Res. 108 (2003)

E.M. Galimov, Icarus 147, 472-476 (2000)

A. Gaudin, E. Dehouck, N. Mangold, Icarus 216, 257-268 (2011)

C. Gillmann, P. Lognonné, M. Moreira, Earth Planet. Sci. Lett. 303, 299-309 (2011)

D.C. Golden, D.W. Ming, C.S. Schwandt, R.V. Morris, S.V. Yang, G.E. Lofgren, Meteorit. Planet. Sci. 35, 457-465 (2000)

D.C. Golden, D.W. Ming, C.S. Schwandt, H.V. Lauer, R.A. Socki, R.V. Morris, G.E. Lofgren, G.A. McKay, Am. Mineral. 86, 370-375 (2001)

J.L. Gooding, M.E. Zolensky, S.J. Wentworth, Meteoritics 26, 135-143 (1991)

D.O. Gough, Sol. Phys. 74, 21-34 (1981)

L.L. Griffith, E.L. Shock, Nature 377, 406-408 (1995)

M. Grott, A. Morschhauser, D. Breuer, E. Hauber, Earth Planet. Sci. Lett. 308, 391-400 (2011)

R.M. Haberle, J. Geophys. Res. 103, 28467-28479 (1998)

R.M. Haberle, F. Forget, A. Colaprete, J. Schaeffer, W.V. Boynton, N.J. Kelly, M.A. Chamberlain, Planet. Space Sci. 56, 251-255 (2008)

I. Halevy, J.W. Head, Punctuated volcanism, transient warming and global change in the late Noachian-Early Hesperian, in Lunar and Planetary Institute Science Conference Abstracts, vol. 43 (2012), p. 1908

I. Halevy, M.T. Zuber, D.P. Schrag, Science 318, 1903 (2007)

I. Halevy, W.W. Fischer, J.M. Eiler, Proc. Natl. Acad. Sci. USA 108, 16895-16899 (2011)

R.P. Harvey, H.Y. McSween, Nature 382, 49-51 (1996)

M.H. Hecht, Icarus 156, 373-386 (2002)

M.H. Hecht, S.P. Kounaves, R.C. Quinn, S.J. West, S.M.M. Young, D.W. Ming, D.C. Catling, B.C. Clark, W.V. Boynton, J. Hoffman, L.P. DeFlores, K. Gospodinova, J. Kapit, P.H. Smith, Science 325, 64-67 (2009) 
T.L. Heet, R.E. Arvidson, S.C. Cull, M.T. Mellon, K.D. Seelos, J. Geophys. Res. 114, E00E04 (2009)

H. Hiesinger, J.W. Head III, J. Geophys. Res. 109, E01004 (2004)

G. Holland, J.M. Saxton, I.C. Lyon, G. Turner, Geochim. Cosmochim. Acta 69, 1359-1370 (2005)

J.A. Hurowitz, S.M. McLennan, Earth Planet. Sci. Lett. 260, 432-443 (2007)

J.A. Hurowitz, W.W. Fischer, N.J. Tosca, R.E. Milliken, Nat. Geosci. 3, 323-326 (2010)

A.P. Ingersoll, Science 168, 972-973 (1970)

B.M. Jakosky, R.O. Pepin, R.E. Johnson, J.L. Fox, Icarus 111, 271-288 (1994)

S.S. Johnson, M.A. Mischna, T.L. Grove, M.T. Zuber, J. Geophys. Res. 113 (2008)

S.S. Johnson, A.A. Pavlov, M.A. Mischna, J. Geophys. Res. 114 (2009)

A.J.T. Jull, C.J. Eastoe, S. Xue, G.F. Herzog, Meteoritics 30, 311-318 (1995)

A.J.T. Jull, J.W. Beck, G.S. Burr, Geochim. Cosmochim. Acta 64, 3763-3772 (2000)

R. Kahn, Icarus 62, 175-190 (1985)

J.F. Kasting, Icarus 94, 1-13 (1991)

J.F. Kasting, Science 276, 1213 (1997)

A.J. King, A.F. Meyer, S.K. Schmidt, Soil Biol. Biochem. 40, 2605-2610 (2008)

L. Kirkland, K. Herr, E. Keim, P. Adams, J. Salisbury, J. Hackwell, A. Treiman, Remote Sens. Environ. 80, 447-459 (2002)

L.P. Knauth, M.J. Kennedy, Nature 460, 728-732 (2009)

A.H. Knoll, M. Carr, B. Clark, D.J. Des Marais, J.D. Farmer, W.W. Fischer, J.P. Grotzinger, S.M. McLennan, M. Malin, C. Schroder, Earth Planet. Sci. Lett. 240, 179-189 (2005)

S.P. Kounaves, M.H. Hecht, J. Kapit, K. Gospodinova, L. DeFlores, R.C. Quinn, W.V. Boynton, B.C. Clark, D.C. Catling, P. Hredzak, D.W. Ming, Q. Moore, J. Shusterman, S. Stroble, S.J. West, S.M.M. Young, J. Geophys. Res. 115, E00E10 (2010a)

S.P. Kounaves, M.H. Hecht, J. Kapit, R.C. Quinn, D.C. Catling, B.C. Clark, D.W. Ming, K. Gospodinova, P. Hredzak, K. McElhoney, J. Shusterman, Geophys. Res. Lett. 37, 09201 (2010b)

V.A. Krasnopolsky, J.P. Maillard, T.C. Owen, R.A. Toth, M.D. Smith, Icarus 192, 396-403 (2007)

M.D. Lane, M.D. Dyar, J.L. Bishop, Geophys. Res. Lett. 31, L19702 (2004)

L.A. Leshin, K.D. McKeegan, P.K. Carpenter, R.P. Harvey, Geochim. Cosmochim. Acta 62, 3-13 (1998)

F. Lippmann, Sedimentary Carbonate Minerals (Springer, Berlin, 1973), p. 228

J.R. Lyons, C. Manning, F. Nimmo, Geophys. Res. Lett. 32 (2005)

G. Macleod, C. McKeown, A.J. Hall, M.J. Russell, in Origins of Life and Evolution of Biospheres, vol. 24 (1994), pp. 19-41

M.C. Malin, K.S. Edgett, Science 290, 1927-1937 (2000)

C.V. Manning, C.P. McKay, K.J. Zahnle, Icarus 180, 38-59 (2006)

A.S. McEwen, L. Ojha, C.M. Dundas, S.S. Mattson, S. Byrne, J.J. Wray, S.C. Cull, S.L. Murchie, N. Thomas, V.C. Gulick, Science 333, 740-743 (2011)

D.S. McKay, E.K. Gibson, K.L. ThomasKeprta, H. Vali, C.S. Romanek, S.J. Clemett, X.D.F. Chillier, C.R. Maechling, R.N. Zare, Science 273, 924-930 (1996)

H.Y. McSween, R.P. Harvey, Int. Geol. Rev. 40, 774-783 (1998)

H.J. Melosh, A.M. Vickery, Nature 338, 487-489 (1989)

C. Meyer, The Mars Meteorite Compendium (NASA Johnson Space Center, Houston, 2011)

J.R. Michalski, P.B. Niles, Nat. Geosci. 3, 751-755 (2010)

T. Mikouchi, E. Koizumi, A. Monkawa, Y. Ueda, M. Miyamoto, Antarct. Meteor. Res. 16, 34-57 (2003)

R.E. Milliken, J.P. Grotzinger, B.J. Thomson, Geophys. Res. Lett. 37, 04201 (2010)

D.W. Mittlefehldt, Meteoritics 29, 214-221 (1994)

R.V. Morris, G. Klingelhofer, C. Schroder, D.S. Rodionov, A. Yen, D.W. Ming, P.A. de Souza, T. Wdowiak, I. Fleischer, R. Gellert, B. Bernhardt, U. Bonnes, B.A. Cohen, E.N. Evlanov, J. Foh, P. Gutlich, E. Kankeleit, T. McCoy, D.W. Mittlefehldt, F. Renz, M.E. Schmidt, B. Zubkov, S.W. Squyres, R.E. Arvidson, J. Geophys. Res. 111, E12S15 (2006)

R.V. Morris, S.W. Ruff, R. Gellert, D.W. Ming, R.E. Arvidson, B.C. Clark, D.C. Golden, K. Siebach, G. Klingelhofer, C. Schroder, I. Fleischer, A.S. Yen, S.W. Squyres, Science 329, 421-424 (2010)

P.S. Mozley, Geology 17, 704-706 (1989)

K.J. Murata, I.I. Friedman, B.M. Madsen, Science 156, 1484 (1967)

S.L. Murchie, J.F. Mustard, B.L. Ehlmann, R.E. Milliken, J.L. Bishop, N.K. McKeown, E.Z. Noe Dobrea, F.P. Seelos, D.L. Buczkowski, S.M. Wiseman, R.E. Arvidson, J.J. Wray, G. Swayze, R.N. Clark, D.J. Des Marais, A.S. McEwen, J.-P. Bibring, J. Geophys. Res. 114 (2009)

J.F. Mustard, B.L. Ehlmann, S.L. Murchie, F. Poulet, N. Mangold, J.W. Head, J.P. Bibring, L.H. Roach, J. Geophys. Res. 114, E00D12 (2009)

G. Neukum, R. Jaumann, H. Hoffmann, E. Hauber, J.W. Head, A.T. Basilevsky, B.A. Ivanov, S.C. Werner, S. van Gasselt, J.B. Murray, T. McCord, The HRSC Team, Nature 432, 971-979 (2004)

W.I. Newman, E.M.D. Symbalisty, T.J. Ahrens, E.M. Jones, Icarus 138, 224-240 (1999) 
H.E. Newsom, Icarus 44, 207-216 (1980)

P.B. Niles, J. Michalski, Nat. Geosci. 2, 215-220 (2009)

P.B. Niles, L.A. Leshin, Y. Guan, Geochim. Cosmochim. Acta 69, 2931-2944 (2005)

P.B. Niles, M.Y. Zolotov, L.A. Leshin, Earth Planet. Sci. Lett. 286, 122-130 (2009)

P.B. Niles, W.V. Boynton, J.H. Hoffman, D.W. Ming, D. Hamara, Science 329, 1334-1337 (2010)

L.E. Nyquist, D.D. Bogard, C.Y. Shih, A. Greshake, D. Stoffler, O. Eugster, Space Sci. Rev. 96, 105-164 (2001)

T. Owen, A. Bar-Nun, Icarus 116, 215-226 (1995)

C. Oze, M. Sharma, Geophys. Res. Lett. 32 (2005)

J.L. Palandri, M.H. Reed, Geochim. Cosmochim. Acta 68, 1115-1133 (2004)

E.M. Parmentier, M.T. Zuber, J. Geophys. Res. 112, E02007 (2007)

R.J. Phillips, M.T. Zuber, S.C. Solomon, M.P. Golombek, B.M. Jakosky, W.B. Banerdt, D.E. Smith, R.M.E. Williams, B.M. Hynek, O. Aharonson, S.A. Hauck Ii, Science 291, 2587-2591 (2001)

R.J. Phillips, B.J. Davis, K.L. Tanaka, S. Byrne, M.T. Mellon, N.E. Putzig, R.M. Haberle, M.A. Kahre, B.A. Campbell, L.M. Carter, I.B. Smith, J.W. Holt, S.E. Smrekar, D.C. Nunes, J.J. Plaut, A.F. Egan, T.N. Titus, R. Seu, Science (2011)

M. Pilkington, R.A.F. Grieve, Rev. Geophys. 30, 161-181 (1992)

W. Pohl, Monogr. Ser. Miner. Depos. 28, 1-13 (1989)

J.B. Pollack, J.F. Kasting, S.M. Richardson, K. Poliakoff, Icarus 71, 203-224 (1987)

S.E. Postawko, W.R. Kuhn, J. Geophys. Res. 91, D431 (1986)

R. Quinn, J. Orenberg, Geochim. Cosmochim. Acta 57, 4611-4618 (1993)

M.C. Rabenhorst, L.P. Wilding, L.T. West, Soil Sci. Soc. Am. J. 48, 125-132 (1984)

A.M. Reid, T.E. Bunch, Meteoritics 10, 317 (1975)

M.I. Richardson, M.A. Mischna, J. Geophys. Res. 110, E03003 (2005)

C.S. Romanek, M.M. Grady, I.P. Wright, D.W. Mittlefehldt, R.A. Socki, C.T. Pillinger, E.K. Gibson, Nature 372, 655-657 (1994)

S.W. Ruff, P.R. Christensen, J. Geophys. Res. 107, 5127 (2002)

S.W. Ruff, P.R. Christensen, R.N. Clark, H.H. Kieffer, M.C. Malin, J.L. Bandfield, B.M. Jakosky, M.D. Lane, M.T. Mellon, M.A. Presley, J. Geophys. Res. 106, 23921-23927 (2001)

M.J. Russell, Ore Geol. Rev. 10, 199-214 (1996)

M.J. Russell, J.K. Ingham, V. Zedef, D. Maktav, F. Sunar, A.J. Hall, A.E. Fallick, J. Geol. Soc. 156, 869-888 (1999)

C. Sagan, G. Mullen, Science 177, 52-56 (1972)

M.R. Salvatore, J.F. Mustard, M.B. Wyatt, S.L. Murchie, J. Geophys. Res. 115, E07005 (2010)

J.M. Saxton, I.C. Lyon, G. Turner, Earth Planet. Sci. Lett. 160, 811-822 (1998)

A. Segura, R. Navarro-Gonzalez, Orig. Life Evol. Biosph. 35, 477-487 (2005)

T.L. Segura, O.B. Toon, A. Colaprete, K. Zahnle, Science 298, 1977-1980 (2002)

R. Shaheen, A. Abramian, J. Horn, G. Dominguez, R. Sullivan, M.H. Thiemens, Proc. Natl. Acad. Sci. (2010)

N.D. Sheldon, Precambrian Res. 147, 148-155 (2006)

P.H. Smith, L.K. Tamppari, R.E. Arvidson, D. Bass, D. Blaney, W.V. Boynton, A. Carswell, D.C. Catling, B.C. Clark, T. Duck, E. DeJong, D. Fisher, W. Goetz, H.P. Gunnlaugsson, M.H. Hecht, V. Hipkin, J. Hoffman, S.F. Hviid, H.U. Keller, S.P. Kounaves, C.F. Lange, M.T. Lemmon, M.B. Madsen, W.J. Markiewicz, J. Marshall, C.P. McKay, M.T. Mellon, D.W. Ming, R.V. Morris, W.T. Pike, N. Renno, U. Staufer, C. Stoker, P. Taylor, J.A. Whiteway, A.P. Zent, Science 325, 58-61 (2009b)

D.E. Smith, M.T. Zuber, M.H. Torrence, P.J. Dunn, G.A. Neumann, F.G. Lemoine, S.K. Fricke, J. Geophys. Res. 114, 05002 (2009a)

S.W. Squyres, J.F. Kasting, Science 265, 744-749 (1994)

B.D. Stanley, M.M. Hirschmann, A.C. Withers, Geochim. Cosmochim. Acta 75, 5987-6003 (2011)

A. Steele, M.D. Fries, H.E.F. Amundsen, B.O. Mysen, M.L. Fogel, M. Schweizer, N.Z. Boctor, Meteorit. Planet. Sci. 42, 1549-1566 (2007)

S.K. Stephens, Carbonate Formation on Mars: Experiments and Models (California Institute of Technology, Pasadena, 1995), p. 276

S.K. Stephens, D.J. Stevenson, G.R. Rossman, Carbonates on Mars: experimental results, in Lunar and Planetary Institute Science Conference Abstracts (1995)

R.E. Stevens, M.K. Carron, Am. Mineral. 33, 31-49 (1948)

B. Sutter, W.V. Boynton, D.W. Ming, P.B. Niles, R.V. Morris, D.C. Golden, H.V. Lauer Jr., C. Fellows, D.K. Hamara, S.A. Mertzman, Icarus 218, 290-296 (2012)

K.L. Tanaka, J.A.P. Rodriguez, J.A. Skinner Jr., M.C. Bourke, C.M. Fortezzo, K.E. Herkenhoff, E.J. Kolb, C.H. Okubo, Icarus 196, 318-358 (2008)

K.L. Tanaka, C.M. Fortezzo, R.K. Hayward, J.A.P. Rodriguez, J.A. Skinner Jr., Planet. Space Sci. 59, 11281142 (2011) 
F. Tian, J.F. Kasting, S.C. Solomon, Geophys. Res. Lett. 36 (2009)

F. Tian, M.W. Claire, J.D. Haqq-Misra, M. Smith, D.C. Crisp, D. Catling, K. Zahnle, J.F. Kasting, Earth Planet. Sci. Lett. 295, 412-418 (2010)

O.B. Toon, T. Segura, K. Zahnle, Annu. Rev. Earth Planet. Sci. 38, 303-322 (2010)

A.H. Treiman, Meteoritics 30, 294-302 (1995)

A.H. Treiman, H.E.F. Amundsen, D.F. Blake, T. Bunch, Earth Planet. Sci. Lett. 204, 323-332 (2002)

J.W. Valley, J.M. Eiler, C.M. Graham, E.K. Gibson, C.S. Romanek, E.M. Stolper, Science 275, 1633-1638 (1997)

W. van Berk, Y. Fu, J. Geophys. Res. 116, E10006 (2011)

J. Vaucher, D. Baratoux, M.J. Toplis, P. Pinet, N. Mangold, K. Kurita, Icarus 200, 39-51 (2009)

P.H. Warren, J. Geophys. Res. 103, 16759-16773 (1998)

S.C. Werner, Icarus 195, 45-60 (2008)

S.C. Werner, Icarus 201, 44-68 (2009)

J.J. Wray, S.L. Murchie, B.L. Ehlmann, R.E. Milliken, K.D. Seelos, E.Z. Noe Dobrea, J.F. Mustard, S.W. Squyres, Evidence for regional deeply buried carbonate-bearing rocks on Mars, in Lunar and Planetary Science Conference Abstracts, vol. 42 (2011), p. 2635

I.P. Wright, M.M. Grady, C.T. Pillinger, Geochim. Cosmochim. Acta 56, 817-826 (1992)

A.S. Yen, R. Gellert, C. Schroder, R.V. Morris, J.F. Bell, A.T. Knudson, B.C. Clark, D.W. Ming, J.A. Crisp, R.E. Arvidson, D. Blaney, J. Bruckner, P.R. Christensen, D.J. DesMarais, P.A. de Souza, T.E. Economou, A. Ghosh, B.C. Hahn, K.E. Herkenhoff, L.A. Haskin, J.A. Hurowitz, B.L. Joliff, J.R. Johnson, G. Klingelhofer, M.B. Madsen, S.M. McLennan, H.Y. McSween, L. Richter, R. Rieder, D. Rodionov, L. Soderblom, S.W. Squyres, N.J. Tosca, A. Wang, M. Wyatt, J. Zipfel, Nature 436, 49-54 (2005)

A.S. Yen, R.V. Morris, B.C. Clark, R. Gellert, A.T. Knudson, S. Squyres, D.W. Mittlefehldt, D.W. Ming, R. Arvidson, T. McCoy, M. Schmidt, J. Hurowitz, R. Li, J.R. Johnson, J. Geophys. Res. 113 (2008)

A.P. Zent, M.H. Hecht, D.R. Cobos, S.E. Wood, T.L. Hudson, S.M. Milkovich, L.P. DeFlores, M.T. Mellon, J. Geophys. Res. 115, E00E14 (2010)

M.Y. Zolotov, E.L. Shock, Geophys. Res. Lett. 32 (2005) 